\title{
Translocation of (ultra)fine particles and nanoparticles across the placenta; $a$ systematic review on the evidence of in vitro, ex vivo, and in vivo studies
}

\author{
Eva Bongaerts ${ }^{1}$, Tim S. Nawrot ${ }^{1,2}$, Thessa Van Pee ${ }^{1}$, Marcel Ameloot ${ }^{3}$ and Hannelore Bové B $^{1,3^{*}}$ (D)
}

\begin{abstract}
Fetal development is a crucial window of susceptibility in which exposure may lead to detrimental health outcomes at birth and later in life. The placenta serves as a gatekeeper between mother and fetus. Knowledge regarding the barrier capacity of the placenta for nanoparticles is limited, mostly due to technical obstacles and ethical issues. We systematically summarize and discuss the current evidence and define knowledge gaps concerning the maternal-fetal transport and fetoplacental accumulation of (ultra)fine particles and nanoparticles. We included 73 studies on placental translocation of particles, of which 21 in vitro/ex vivo studies, 50 animal studies, and 2 human studies on transplacental particle transfer. This systematic review shows that (i) (ultra)fine particles and engineered nanoparticles can bypass the placenta and reach fetal units as observed for all the applied models irrespective of the species origin (i.e., rodent, rabbit, or human) or the complexity (i.e., in vitro, ex vivo, or in vivo), (ii) particle size, particle material, dose, particle dissolution, gestational stage of the model, and surface composition influence maternal-fetal translocation, and (iii) no simple, standardized method for nanoparticle detection and/or quantification in biological matrices is available to date. Existing evidence, research gaps, and perspectives of maternal-fetal particle transfer are highlighted.
\end{abstract}

Keywords: Engineered, (ultra)fine particles, Nanoparticles, Pregnancy, Placenta, Maternal-fetal transfer

\section{Background}

Pregnant women and developing embryos/fetuses comprise a particularly vulnerable population, as nanoparticles (NPs) that infiltrate the bloodstream may reach the placenta and possibly the fetus [1]. Such in utero exposure may not only influence fetal development and induce adverse pregnancy outcomes, but it can also adversely affect health in later life since the etiology of

\footnotetext{
* Correspondence: hannelore.bove@uhasselt.be

'Centre for Environmental Sciences, Hasselt University, Agoralaan Building D, 3590 Diepenbeek, Belgium

${ }^{3}$ Biomedical Research Institute, Hasselt University, Agoralaan Building C, 3590 Diepenbeek, Belgium

Full list of author information is available at the end of the article
}

diseases in adulthood may have a fetal origin [2], as postulated in the Developmental Origins of Health and Disease hypothesis [3]. Various epidemiological studies identified associations between prenatal exposure to (ultra)fine particles and adverse health outcomes (i) at birth including an increased risk of low birth weight $(<2500$ g) $[4,5]$ and preterm birth (<37 weeks of gestation) $[6$, $7]$, and (ii) later in life such as cardiovascular disease [8, 9], respiratory problems $[10,11]$, and neurodevelopmental alterations $[12,13]$. (Ultra)fine particles refer to the particles that are incidentally generated and emitted in the (outdoor) air, often as by-products of fossil fuel combustion or industrial emission. In contrast, NPs are nanosized particles manufactured through controlled 
engineering processes [14]. Concerning the latter, Manangama et al. showed a significant association between maternal occupational NP exposure and small for gestational age (birth weight $<10$ th percentile for gestational age) [15]. Appropriately, the question arises if, during pregnancy, particles can translocate from the mother towards the developing fetus. To our knowledge, this is the first systematic review synthesizing all literature regarding the maternal-fetal transfer of (ultra)fine particles and NPs in in vitro, ex vivo, and in vivo settings. The systematic review aims to (i) evaluate the translocation of (ultra)fine particles and NPs towards and across the placenta in in vitro cellular barriers, ex vivo placental perfusion models, in vivo animal, and in vivo human studies, (ii) summarize the exploited analytical techniques to determine maternal-fetal NP translocation, and (iii) identify gaps and further research needs.

\section{Methods}

The systematic review was processed according to the Preferred Reporting Items for Systematic reviews and
Meta-Analyses (PRISMA) statement [16]. In accordance with the guidelines, our systematic review protocol was published by the International Prospective Register of Systematic Reviews (PROSPERO) on April 28th, 2020 (CRD42020167478, Additional file 1).

\section{Search strategy}

The search strategy used to identify relevant studies on the maternal-fetal transfer of (ultra)fine particles and engineered NPs was made up of four stages, as depicted in Fig. 1. In the first stage, articles were identified through a comprehensive literature search using two electronic bibliographic databases: MEDLINE (PubMed interface (www.pubmed.ncbi.nlm.nih.gov)) and Science Citation Index Expanded (Web of Science interface (www.webofknowledge.com/WOS)). The full search strategy was based on the search components "placenta", "particles", and "translocation". Literature search strategies based on Boolean operators were developed using related $\mathrm{MeSH}$ terms and text words (Additional file 2). To ensure literature saturation, reference lists in key

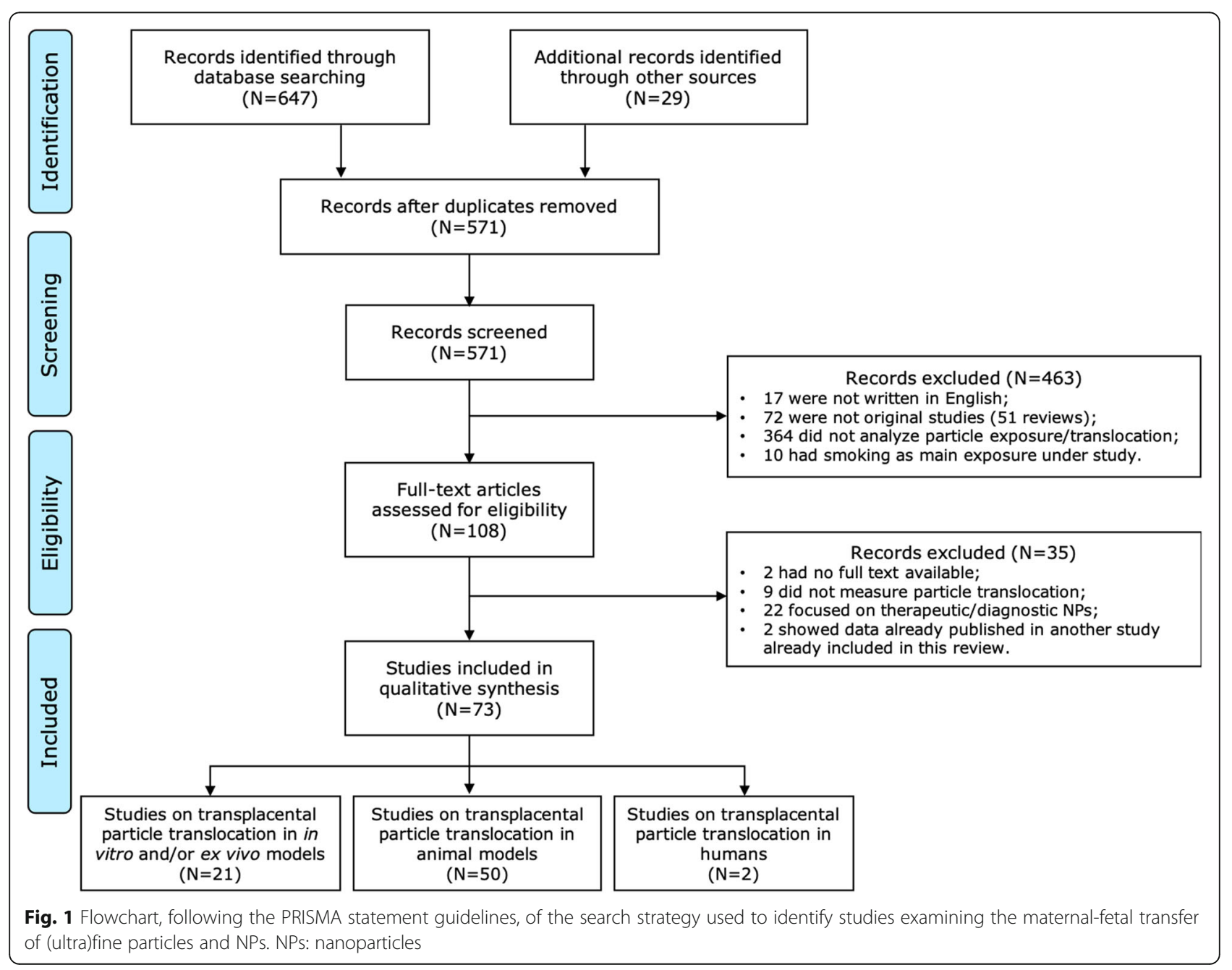


review papers and included studies were screened to find additional eligible publications that were not retrieved from our initial database searches. The literature search covered articles published in English between January 1st, 1940 and August 11th, 2020.

\section{Selection criteria}

We included human studies and animal studies relevant to human health that addressed the translocation of (ultra)fine particles or NPs across the placenta in an in vitro, ex vivo, and in vivo context. To maintain the focus on air pollutants and engineered nanomaterials in particulate form, we excluded articles examining exposure to tobacco smoke, secondhand smoke, volatile organic components (e.g., benzene, styrene, or xylene) or other volatile substances (e.g., carbon monoxide (CO), ozone $\left(\mathrm{O}_{3}\right)$, nitrogen dioxide $\left(\mathrm{NO}_{2}\right)$, or sulfur dioxide $\left.\left(\mathrm{SO}_{2}\right)\right)$, and nanomaterials characterized by a high aspect ratio (e.g., nanotubes, nanosheets, or nanowires). Additionally, therapeutic NPs were excluded since these systems are specifically fabricated to (i) achieve targeted and increased placental uptake to treat placental complications (e.g., placenta previa-accreta) [17], (ii) limit transplacental transfer to protect the developing fetus while treating the pregnant mother $[18,19]$, or (iii) allow transplacental transfer to enable prenatal treatment of congenital diseases (e.g., congenital adrenal hyperplasia or fetal cardiac arrhythmia) while avoiding severe maternal side effects [20,21]; whereas we want to maintain the focus on unintentional/environmental exposures.

\section{Selection of studies}

Two reviewers (EB and TVP) independently screened the titles and abstracts of all identified papers to exclude studies that did not fulfill one or more of the a priori set inclusion criteria. Any disagreement was resolved through discussion. If no consensus was reached, a third reviewer $(\mathrm{HB})$ was consulted. In the third stage, the full text of selected papers was retrieved and underwent a second screening to see which articles were eligible for inclusion.

\section{Data extraction process}

In the fourth stage, selected studies were grouped according to model and characterized as in vitro, ex vivo, or in vivo (i.e., human or animal) study. The following data were extracted and registered in a predesigned data extraction form: authors, model characteristics, experimental information (e.g., nature of particle exposure, particle size, particle material, surface modification, exposure route, exposure period, and dose), and main findings (e.g., the observation of translocation, and analytical methods used to visualize or quantify particle transfer).

\section{Synthesis of results}

The diversity in, among others, species origin (i.e., rodent, rabbit, or human) or complexity (i.e., in vitro, ex vivo, or in vivo) of the applied model, administration route and particle dose, exposure assessment, and analytical detection method, did not allow to carry out a comparative quantitative analysis. Instead, we provided a qualitative overview of the results on the maternal-fetal transfer of (ultra)fine particles and NPs. Narrative result synthesis was achieved via three different steps: (i) summarizing information on the characteristics of included studies in tables per study model, (ii) identifying the maternal-fetal transfer of a given particle, and (iii) grouping those confirmed translocation situations as quantitative or qualitative.

\section{Results}

\section{Study selection}

The initial literature search was completed in January 2020 and re-run in August 2020. A total of 647 articles were identified using PubMed $(N=296)$ and Web of Science $(N=351)$. Additionally, 29 articles were retrieved from the reference list of included reviews $(N=18)$ and other studies $(N=11)$. In total, 105 duplicates were removed using the EndNote software. Titles and abstracts of 571 papers were screened, and 108 full-text papers were assessed for eligibility. Thirty-five articles were excluded because they did not fulfill the following predetermined inclusion criteria; 2 had no full text available, 9 did not measure particle translocation across the placenta, 22 focused on diagnostic/therapeutic NPs, and 2 showed data already published in another included study. The final selection of 73 articles studying transplacental particle transfer included: (i) 21 studies using the ex vivo placental perfusion model and/or in vitro cell line, (ii) 50 animal model studies, and (iii) 2 studies in a human population (Fig. 1).

\section{Study characteristics}

We have summarized the existing evidence on the maternal-fetal transfer of (ultra)fine particles and NPs in in vitro placental barriers (Table 1), ex vivo placental perfusion models (Table 2), in vivo animal models (Table 3), and humans (Table 4). The characteristics of the included studies are summarized in Fig. 2.

\section{In vitro maternal-fetal particle transfer}

As summarized in Table 1, a total of 15 in vitro cell line studies investigated the maternal-fetal transfer of NPs and (ultra)fine particles. Particle uptake was studied using trophoblast cells grown to confluence on the bottom of a well or Petri dish [29, 30]. Moreover, to study transplacental transfer, cells were cultured on Transwell inserts, which consist of a permeable 


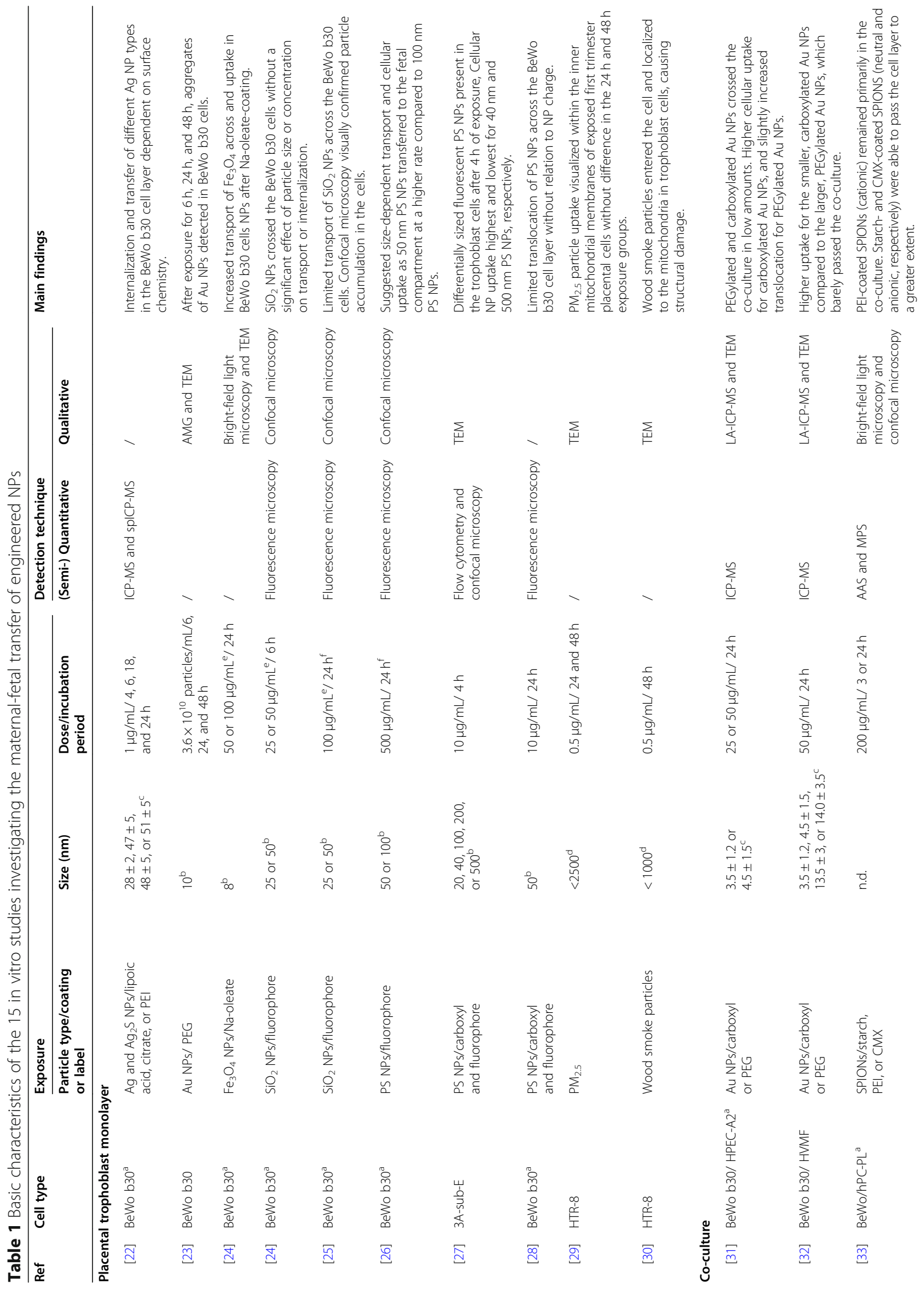




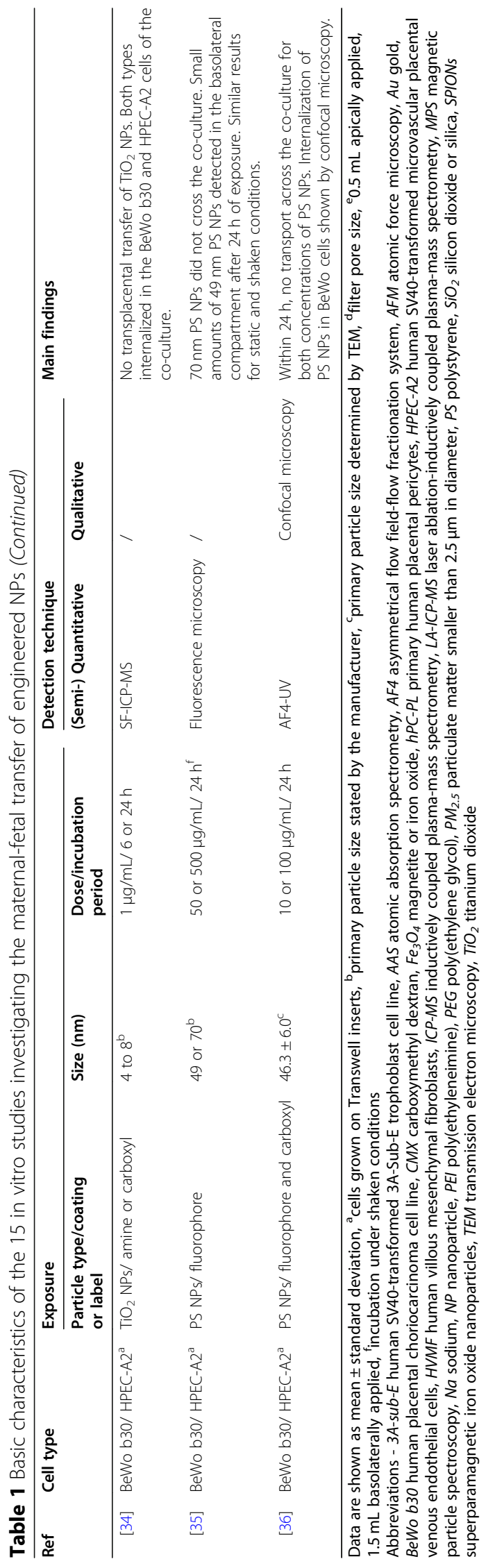




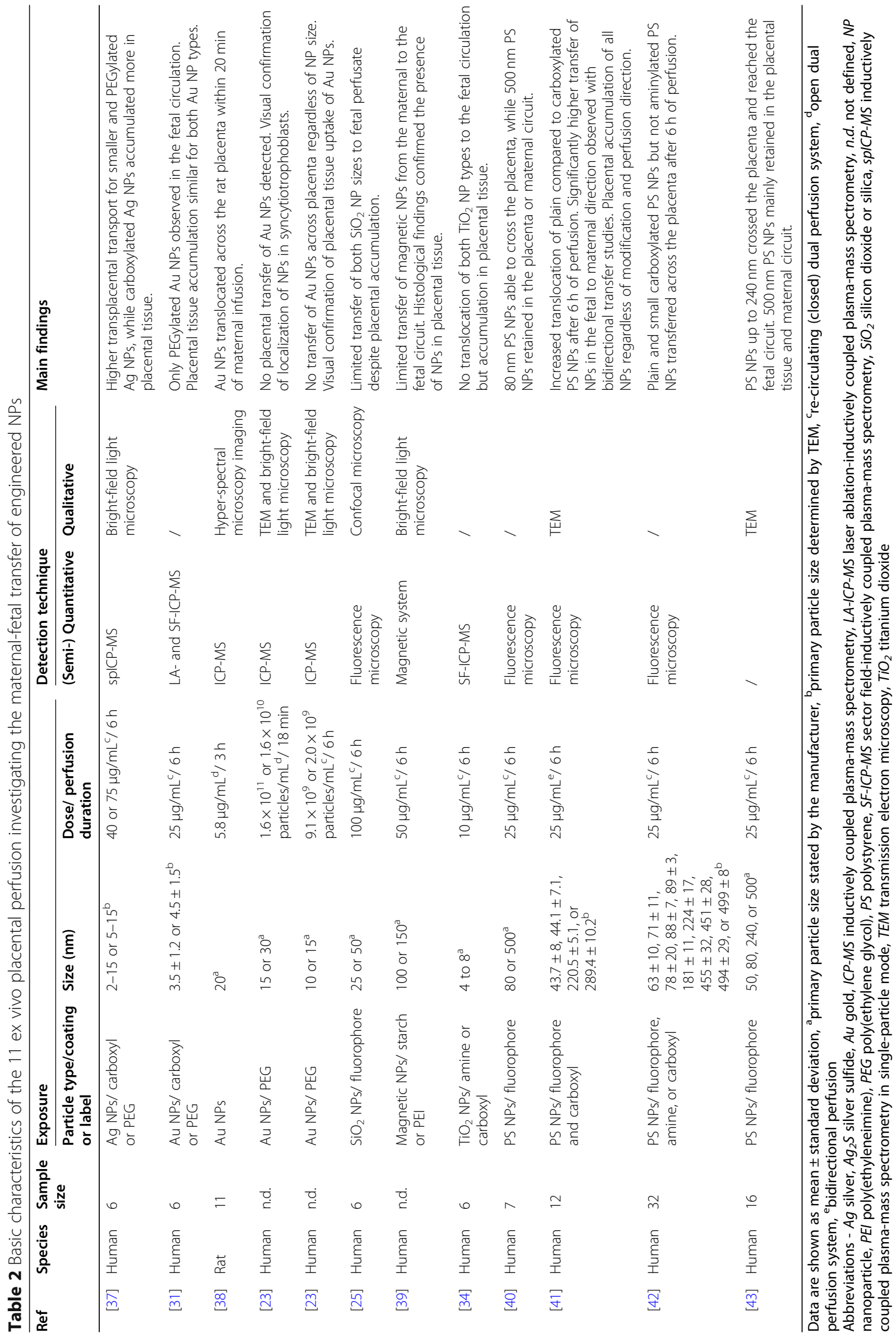




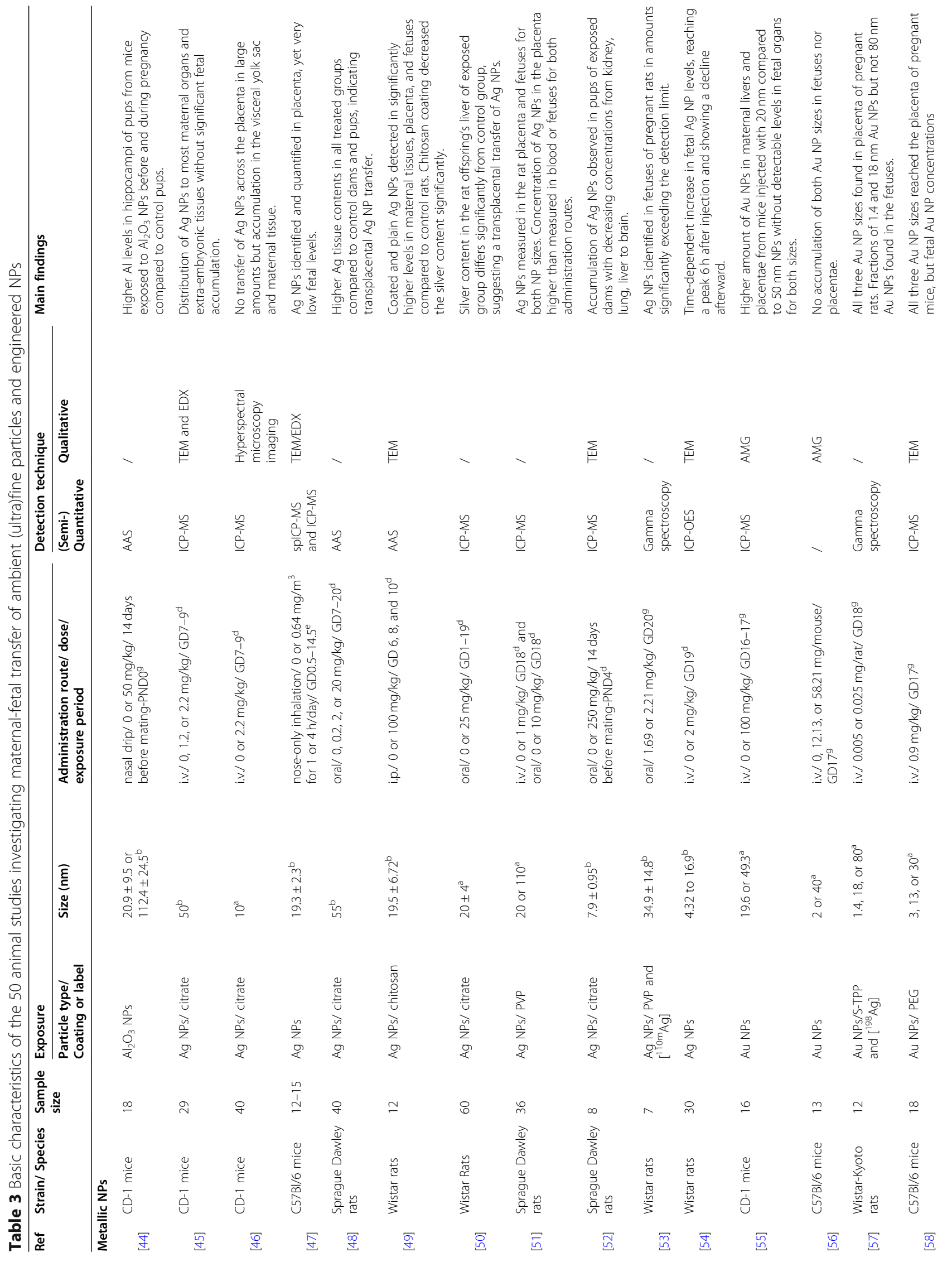




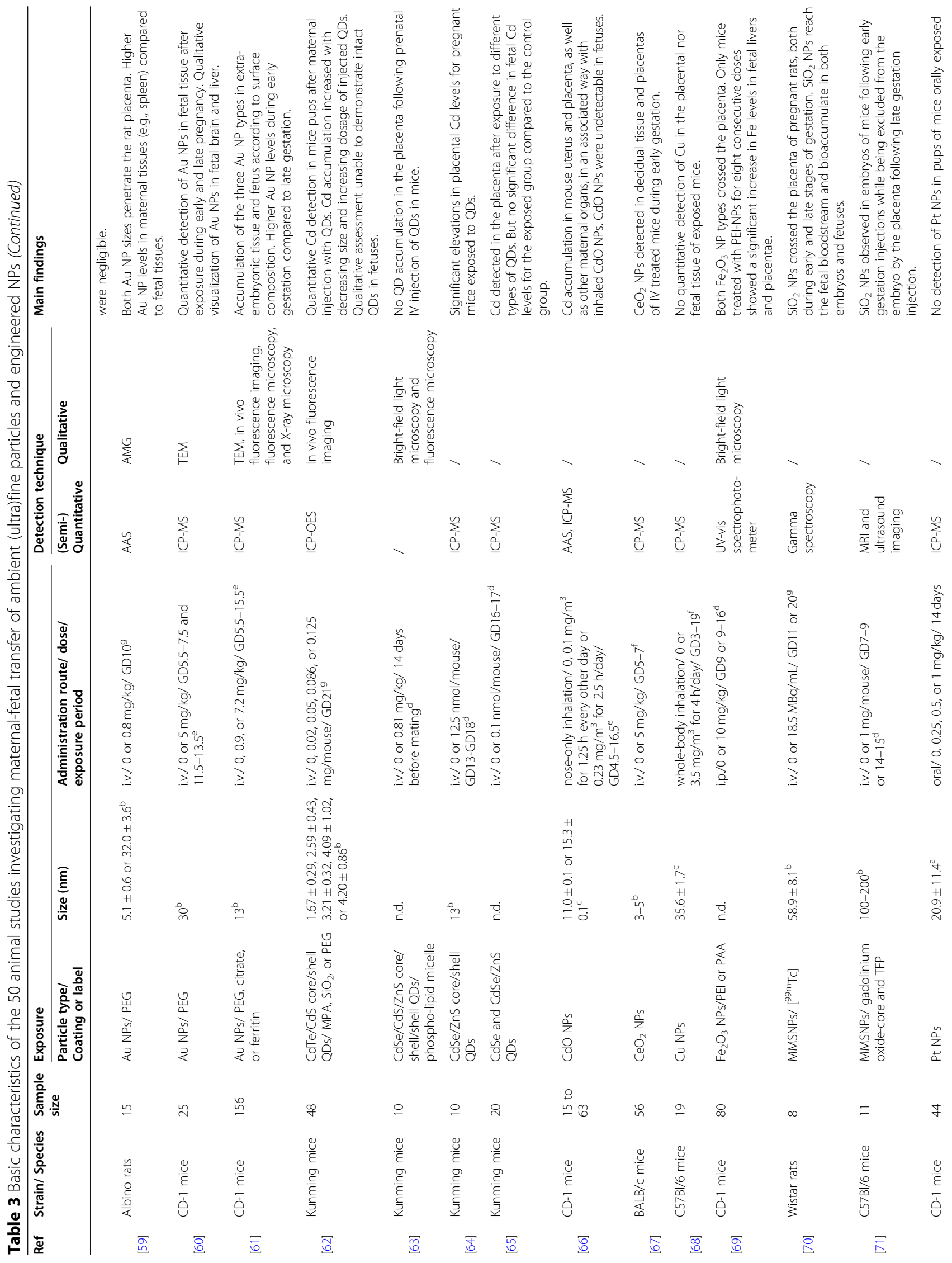




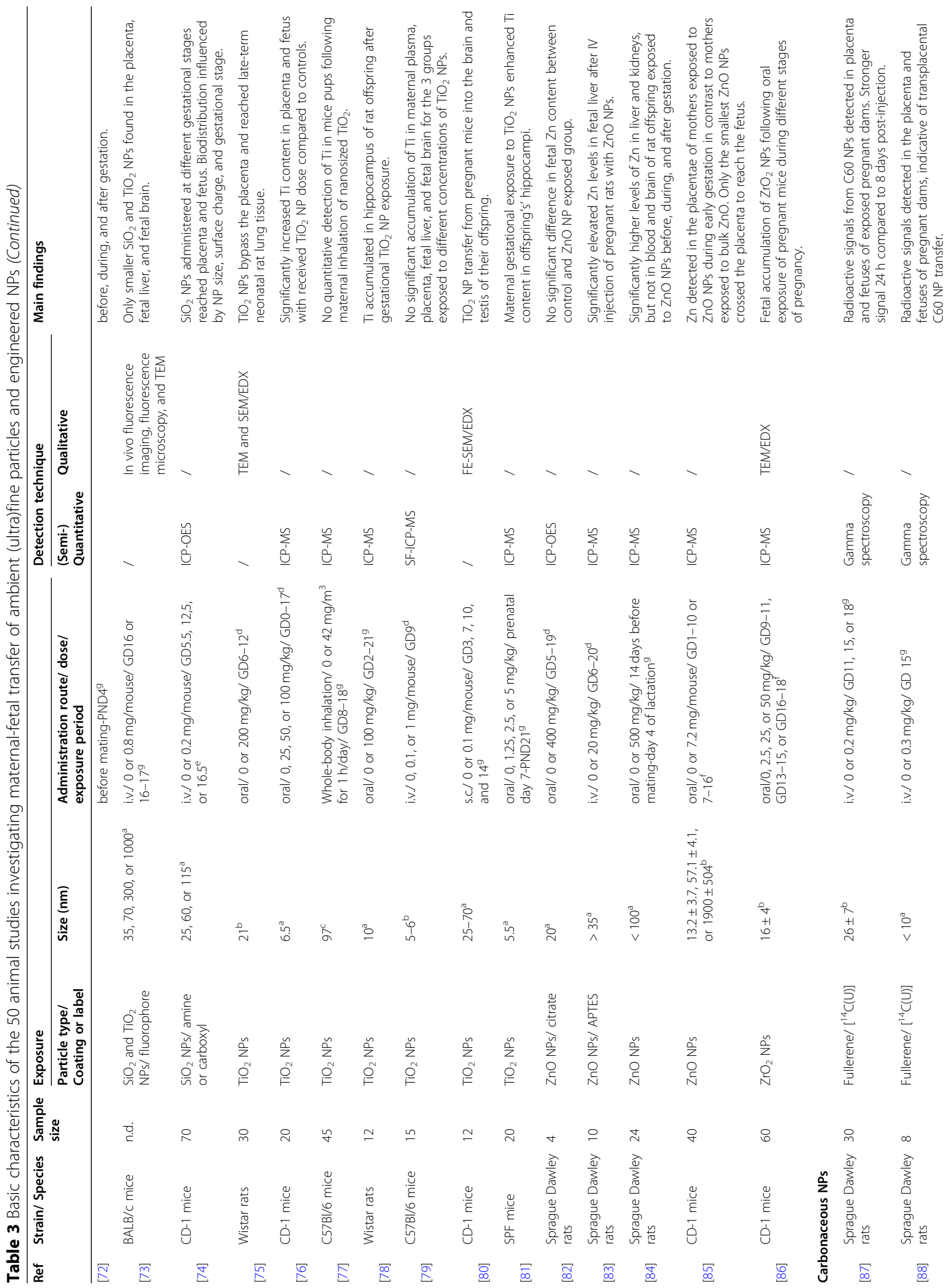




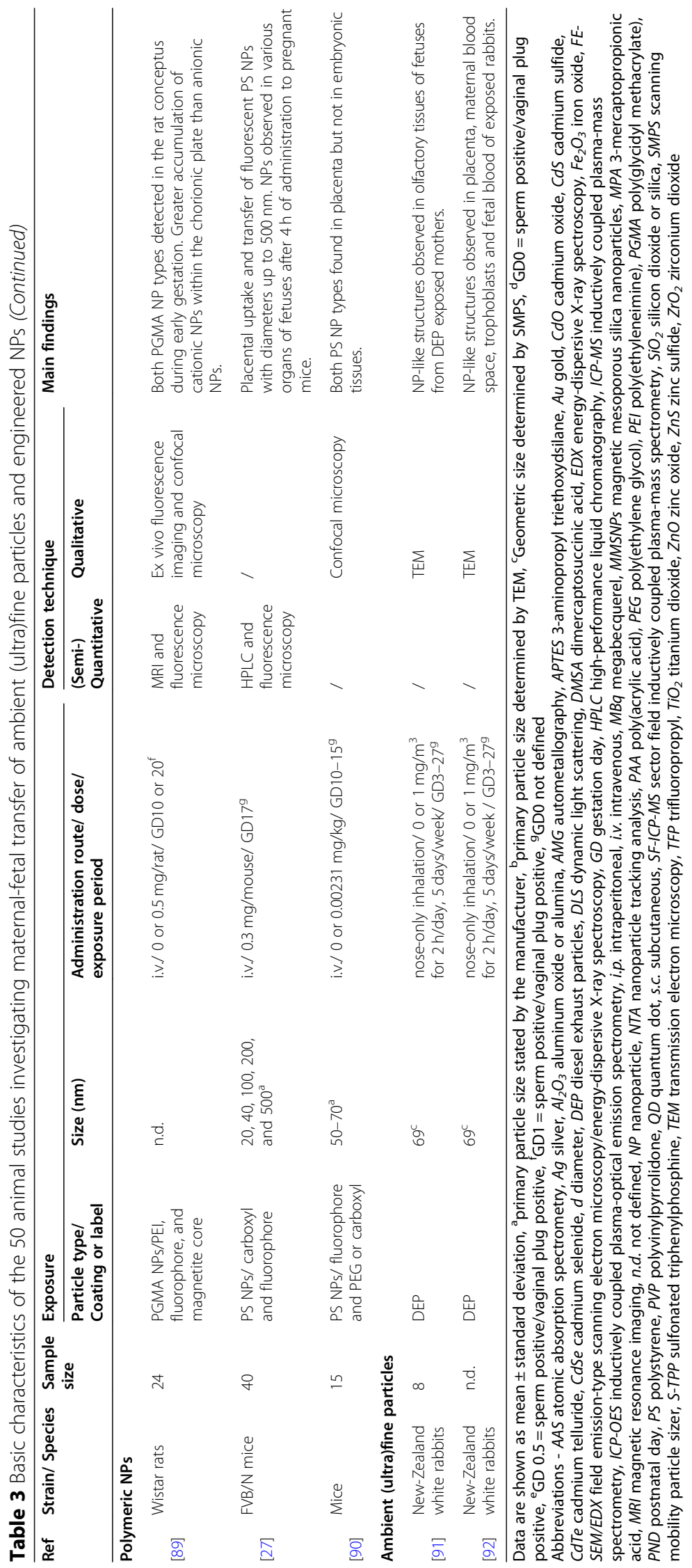


Table 4 Basic characteristics of the human study included in the present systematic review investigating the maternal-fetal transfer of ambient (ultra)fine particles

\begin{tabular}{|c|c|c|c|c|c|c|c|}
\hline \multirow[t]{2}{*}{ Ref } & \multirow{2}{*}{$\begin{array}{l}\text { Sample } \\
\text { size }\end{array}$} & \multicolumn{3}{|l|}{ Exposure } & \multicolumn{2}{|l|}{ Detection technique } & \multirow[t]{2}{*}{ Main findings } \\
\hline & & Particle & Route & Dose & Quantitative & Qualitative & \\
\hline$\overline{[1]}$ & 20 & $\mathrm{BC}$ particles & $\begin{array}{l}\text { Real-life } \\
\text { exposure }\end{array}$ & $0.6-2.4 \mu \mathrm{g} / \mathrm{m}^{3} \mathrm{a}$ & $\begin{array}{l}\text { Two-photon fs pulsed } \\
\text { laser microscopy }\end{array}$ & TEM & $\begin{array}{l}\text { Ambient } B C \text { particles found in all screened } \\
\text { placentas and positively associated with the } \\
\text { mother's residential BC exposure during } \\
\text { pregnancy. }\end{array}$ \\
\hline [93] & 100 & Metallic NPs & $\begin{array}{l}\text { Real-life } \\
\text { exposure }\end{array}$ & n.d. & ICP-OES & SEM/EDX & $\begin{array}{l}\text { High prevalence of essential trace elements } \mathrm{Cu} \text {, } \\
\mathrm{Fe} \text {, and } \mathrm{Zn} \text { in the nano/ion fraction observed in } \\
\text { amniotic fluid of pregnant women. In contrast, } \\
\text { low concentrations and low prevalence of other } \\
\text { elements. No conclusions on transplacental NP } \\
\text { transfer. }\end{array}$ \\
\hline
\end{tabular}

Abbreviations - BC black carbon, $C$ u copper, $F e$ iron, fs femtosecond, ICP-OES inductively coupled plasma-optical emission spectrometry, $m 3$ cubic meter, $\mu m$ micrometer, n.d. not defined, NPs nanoparticles, SEM/EDX scanning electron microscopy/energy-dispersive X-ray spectroscopy, TEM transmission electron microscopy

apredominantly inhaled

membrane separating an apical and a basolateral compartment. Transwells were used to study uptake and transplacental transport of NPs across (i) placental trophoblast monolayers of human placental choriocarcinoma (BeWo b30) cells that strongly resemble cytotrophoblast cells $(N=6)$ [22-26, 28], human SV40transformed trophoblast (3A-sub-E) cells $(N=1)$ [27], or human first trimester trophoblast cells (HTR-8/SVneo $\left(\right.$ ATCC $\left.\left.^{\ominus}, \mathrm{CRL}^{-3271^{\mathrm{rm}}}\right)\right)(N=2)[29,30]$ (ii) co-cultures of trophoblastic cells (i.e., BeWo b30) and endothelial cells (i.e., primary human placental pericytes (hPC-PL) or human SV40-transformed microvascular placental venous endothelial cells (HPEC-A2) $(N=5)$ [31, 33-36], and (iii) a $3 \mathrm{D}$ co-culture of trophoblastic cells (i.e., BeWo b30) and fibroblastic cells (i.e., human villous mesenchymal fibroblasts) $(N=1)$ [32]. Transwell inserts were made from polycarbonate [31, 33-36] or polyethylene terephthalate [34] with a $0.4 \mu \mathrm{m}[22-26,28]$ or $3 \mu \mathrm{m}$
[31, 33-36] pore size. Moreover, a total of 4 studies [31, 34-36] pre-coated the insert with human placental collagen IV to aid cell adherence and growth. Almost all in vitro studies adopted a $24 \mathrm{~h}$ NP incubation period, while other studies used $4 \mathrm{~h}$ [27], $6 \mathrm{~h}$ [24], or $48 \mathrm{~h}[29,30]$ of incubation. The in vitro translocation of 8 different engineered NP types was studied in the included articles: 7 metallic NP types (i.e., silver $(\mathrm{Ag})$, silver sulfide $\left(\mathrm{Ag}_{2} \mathrm{~S}\right)$, gold $(\mathrm{Au})$, magnetite $\left(\mathrm{Fe}_{3} \mathrm{O}_{4}\right)$, silicon dioxide $\left(\mathrm{SiO}_{2}\right)$, titanium dioxide $\left(\mathrm{TiO}_{2}\right)$, superparamagnetic iron oxide NPs (SPIONs)), and one polymeric NP type, namely polystyrene (PS) NPs. Moreover, the transplacental in vitro translocation of airborne (ultra)fine particles, namely wood smoke particles [30] and particulate matter $\leq 2.5 \mu \mathrm{m}$ $\left(\mathrm{PM}_{2.5}\right)$ [29], was assessed.

Overall, the NP transport from the apical to the basolateral side was limited. Aengenheister et al. showed a

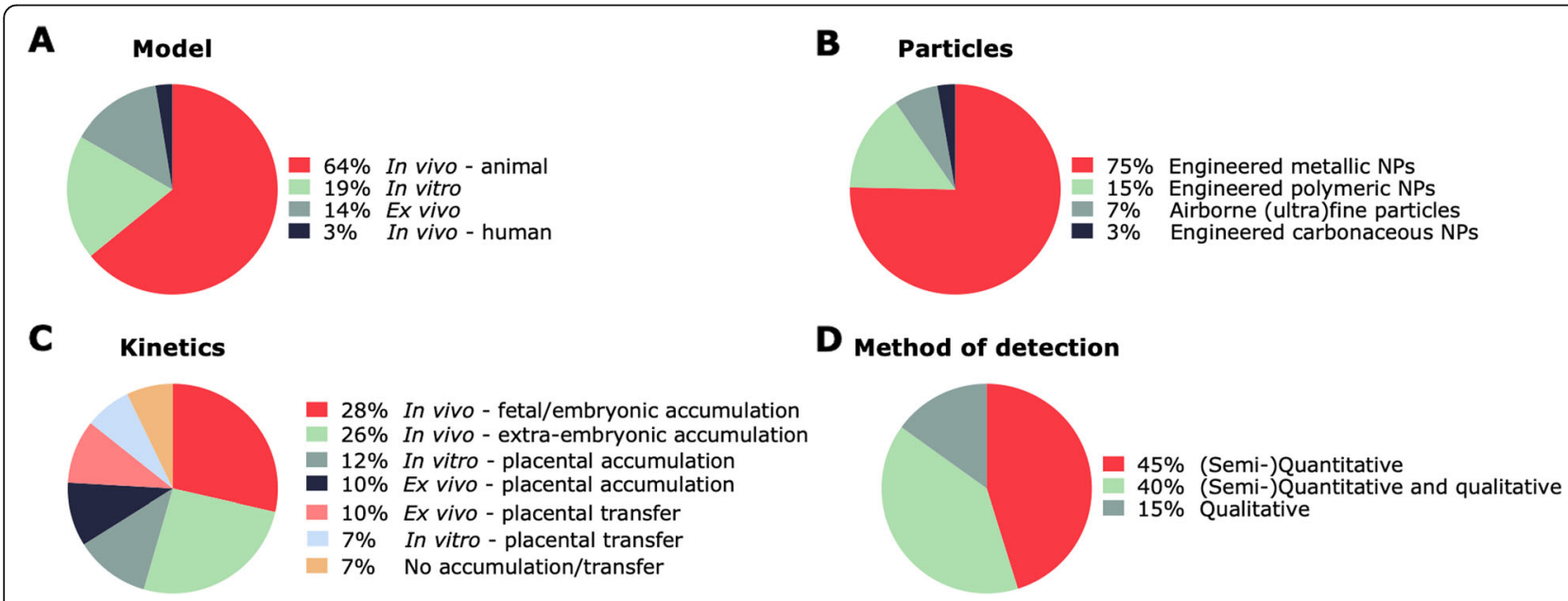

Fig. 2 Pie charts describing the characteristics of the included studies. Different models (a) were used to assess if (ultra)fine particles and NPs (b) can bypass the placenta (c) using a variety of detection methods (d). NPs: nanoparticles 
translocation success of 0.2 and $1.3 \%$ across a BeWo b30 monolayer, 0.1 and 3.6\% across an HPEC-A2 monolayer, and 0.1 and $0.6 \%$ across the detailed co-culture, respectively for $3 \mathrm{~nm}$ poly(ethylene glycol) (PEG)-coated and 4 $\mathrm{nm}$ carboxylated Au NPs [31]. Additionally, the same research group reported a negligible transplacental transfer of carboxylated and aminylated $\mathrm{TiO}_{2} \mathrm{NPs}$ across similar cellular barriers [34]. Multiple studies focused on the effect of particle size and concluded a size-dependent particle transport as larger particles were primarily internalized by the cells with limited transfer to the basolateral compartment [26, 27, 32]. Moreover, surface modification was found to steer particle transport and cell-particle interactions [22, 24, 31-33]. Sodium oleate-coating increased both transcellular transport and cellular uptake, while PEGylation or poly(ethyleneimine) (PEI)-coating resulted in enhanced placental cell association and thus less transport. On the other hand, carboxylation, starch-, or dextran-coating were shown to enhance the transport across the cell barrier while decreasing cell-particle interactions and thus internalization [22, 24, 31-33].

Only 2 studies examined the transfer of ambient air pollution particles across the in vitro placental barrier, more specifically across placental first-trimester trophoblast cells [29, 30]. Both wood smoke particles [30] and $\mathrm{PM}_{2.5}$ [29] accumulated in the exposed placental cells as observed by transmission electron microscopy (TEM).

\section{Ex vivo maternal-fetal particle transfer in placental perfusion models}

Table 2 gives an overview of the 11 included studies on maternal-fetal particle transfer that employed an ex vivo placental perfusion model to mimic the maternal and fetal blood circulation in the placenta. All placental surrogate models used human term placentae, except for one study that used a rat placenta to investigate transplacental particle transfer [38]. Almost all included studies adopted a $6 \mathrm{~h}$ placental perfusion duration $(N=10)$ with the most frequently used NPs being PS $(N=4)$ [40-43] and $\mathrm{Au}(N=3)[23,31,38]$. A total of 4 studies combined results from in vitro cell barriers and ex vivo placental perfusion studies to gain additional insights on the kinetics of particles at the placenta [23, 25, 31, 34]. Overall, the ex vivo placental transfer studies reported a substantial decrease in particle concentration in the maternal perfusate over time, without a corresponding increase in the fetal circulation, indicating NP accumulation in the placental tissue. Accordingly, accumulation of $\mathrm{Au}$ NPs [23, 31], $\mathrm{SiO}_{2}$ NPs [25], and $\mathrm{TiO}_{2}$ NPs [34] was observed in the human placenta, both in vitro and ex vivo. $\mathrm{Au}$ NPs [31] and $\mathrm{SiO}_{2}$ NPs [25] were mainly found in the outer surface of the chorionic villi (i.e., syncytiotrophoblasts), which is in agreement with the observed apical accumulation of the NPs in a BeWo cell monolayer. After $6 \mathrm{~h}$ of perfusion, very limited transfer of small (3-4 nm) PEGylated Au NPs [31], and $\mathrm{SiO}_{2}$ NPs $(25$ and $50 \mathrm{~nm})$ [25] was observed in the fetal circulation. For example, after $6 \mathrm{~h}$ of perfusion, a placental accumulation of $4-7 \mu \mathrm{g} / \mathrm{g}$ and $2-14 \mu \mathrm{g} / \mathrm{g}$ was observed for $3 \mathrm{~nm}$ PEGylated and $4 \mathrm{~nm}$ carboxylated Au NPs, respectively, while the respective particle concentration in the fetal perfusate was only $0.0031 \mu \mathrm{g} / \mathrm{mL}$ and $0 \mu \mathrm{g} / \mathrm{mL}$ [31]. As observed for in vitro studies, an association between placental transfer and particle size is present; an increased placental transfer was observed for perfusions with smaller particle sizes [37, 40-43]. For instance, Wick et al. found that PS NPs up to $240 \mathrm{~nm}$ were able to cross the placenta and reach the fetal circulation already after a few minutes of perfusion, while $500 \mathrm{~nm}$ PS NPs were mainly retained in the placental tissue and maternal circuit [43]. 4 included ex vivo perfusion studies emphasized the effect of surface modification (e.g., PEGylation and carboxylation) on the transplacental passage of engineered NPs [31, 37, 41, 42]. The overall consensus was that PEGylation increases the transplacental particle transport, while carboxylation (e.g., COONaand $\mathrm{COOH}$-modification) resulted in enhanced placental accumulation. One study also reported increased placental accumulation of aminylated compared to carboxylated $\mathrm{TiO}_{2} \mathrm{NPs}$ [34].

\section{In vivo maternal-fetal particle transfer in animal models} In total, 49 animal studies on maternal-fetal particle transfer were included. Forty-three studies showed quantitatively and/or qualitatively that particles reached the placenta after gestational exposure, among which 16 studies observed bioaccumulation of nanosized particles in tissues collected during the embryonic (i.e., organogenesis) and/or fetal period (Table 3). As depicted in Fig. 3a, rodents were the primary animal model used in the included studies (either mouse $(N=29)$ or rat $(N=$ $18)$ ), whereas only 2 studies used rabbits as a model for gestational particle translocation [91, 92]. Moreover, the latter are the only studies examining transplacental translocation of airborne (ultra)fine particles, whereas the remainder of in vivo animal studies focused on engineered NPs.

\section{Engineered NPs}

A total of 48 animal studies examined the transplacental transfer of engineered NPs, including (i) metallic NPs $(N=43)$ (i.e., $\mathrm{Ag}$, alumina $\left(\mathrm{Al}_{2} \mathrm{O}_{3}\right)$, Au, quantum dots (QDs), cadmium oxide $(\mathrm{CdO})$, cerium dioxide $\left(\mathrm{CeO}_{2}\right)$, $\mathrm{Cu}$ (copper), iron oxide $\left(\mathrm{Fe}_{2} \mathrm{O}_{3}\right)$, platinum $(\mathrm{Pt}), \mathrm{SiO}_{2}$, $\mathrm{TiO}_{2}$, and zinc oxide $(\mathrm{ZnO})$, zirconium dioxide $\left(\mathrm{ZrO}_{2}\right)$ NPs), (ii) carbonaceous NPs $(N=2)$ (i.e., fullerene (C60)), and (iii) polymeric NPs $(N=3)$ (i.e., poly(glycidyl methacrylate) (PGMA), and PS) (Table 3). Fetal/ 
A

Animal model

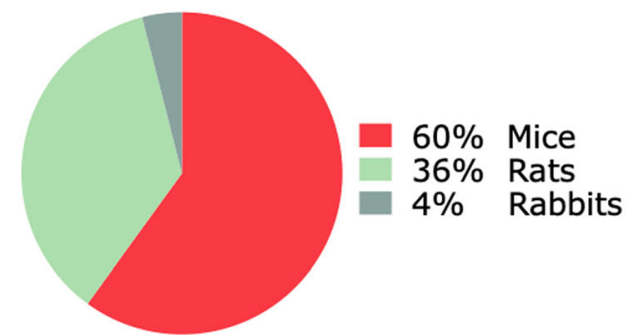

B
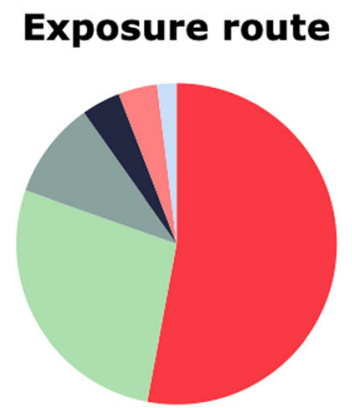

$53 \%$ Intravenous injection

$27 \%$ Oral exposure

$10 \%$ Nose-only exposure

$4 \%$ Whole-body exposure

$4 \%$ Intraperitoneal injection

$2 \%$ Subcutaneous injection

Fig. 3 Pie charts describing the characteristics of the animal studies included in the review. In vivo maternal-fetal particle transfer was assessed in animal models (a) exposed to (ultra)fine particles and NPs via different methods of administration (b). NPs: nanoparticles

embryonic NP accumulation was observed in 32 of the included animal studies, more specifically NPs were detected in the fetal brain $[27,44,48,52,60,73,78,80,81$, 91], fetal liver [27, 48, 50, 52, 60, 69, 73, 83, 84, 86], fetal lung $[27,48,52,75]$, fetal kidney [48, 52, 84], fetal gastrointestinal tract (GIT) [88], and fetal blood [92]. The preferred method for NP administration was intravenous (i.v.) injection $(N=27)$ or gavage $(N=14)$ (Fig. $3 \mathrm{~b})$. The i.v. route is preferred to examine tissue distribution and elimination of NPs while avoiding absorption by the GIT and first-pass elimination in the liver; on the other hand, the oral route is used to assess the ingestion of NPs. Fennell et al. used both i.v. injection and oral administration to expose pregnant rats to $20 \mathrm{~nm}$ and 110 $\mathrm{nm}$ Ag NPs, and showed increased placental Ag NP levels compared to fetal levels regardless of the administration route [51]. Despite inhalation exposure being the primary route in environmental and occupational settings, only 6 animal studies $[47,66,68,77,91,92]$ examined particle translocation following this exposure route. While the studies are limited, the conclusion is unambiguous. All studies except two [68, 77] showed the translocation of Ag NPs [47], CdO NPs [66], and DEPs $[91,92]$ to the placenta and/or fetus following maternal inhalation exposure. In total, 7 included in vivo animal studies revealed a size- or dose-dependent distribution of NPs from mother to fetus, meaning that smaller particles administered in higher doses tend to accumulate more in placental and embryonic/fetal tissue [27, 46, 55, 57, 62, 73, 85]. For instance, measured cadmium (Cd) levels in mice pups were positively associated with the injected $\mathrm{CdTe} / \mathrm{CdS}$ QD dose their mothers received. Moreover, a smaller QD size was found to be associated with increased accumulation of $\mathrm{Cd}$ in the pups [62]. Also, 1.4, 18, and $80 \mathrm{~nm}$ negatively charged Au NPs were found in placentae and amniotic fluid samples of i.v. injected pregnant rats. Only fractions of the initial dose of 1.4 and $18 \mathrm{~nm} \mathrm{Au} \mathrm{NPs} \mathrm{reached} \mathrm{the} \mathrm{fetal} \mathrm{tissue,} \mathrm{sug-}$ gesting a size-dependent maternal-fetal translocation of $\mathrm{Au}$ NPs [57]. The effect of surface charge on transplacental transfer of engineered NPs was discussed in cited studies $[69,74,89]$. Polymeric NPs coated with PEI (i.e., cationic polymer) preferentially accumulate in the rat placenta over negatively charged polymeric NPs [89] as confirmed by Di Bona et al. who showed an increased placental crossing and consequent elevated fetal levels of PEI-coated $\mathrm{Fe}_{2} \mathrm{O}_{3}$ NPs in i.v. injected pregnant mice as opposed to negatively charged poly(acrylic acid) (PAA)-coated $\mathrm{Fe}_{2} \mathrm{O}_{3}$ NPs [69]. Additional studies on surface composition were included [49, 61, 90]; one showed a reduction in maternal-fetal transfer after chitosancoating of Ag NPs [49]. Other studies reported a timedependent accumulation of Ag NPs, $\mathrm{CeO}_{2} \mathrm{NPs}$, and fullerenes as they found that the fetal NP concentration increased over time, reached a peak, and then declined $[54,67,87]$. Moreover, critical exposure windows during gestation were evaluated by defining changes in particle transfer after varying the day of NP exposure $[60,61,70$, $71,87]$. Pregnant rats were divided into five groups and differently exposed with radioactively-labeled fullerenes $\left({ }^{14} \mathrm{C}(\mathrm{C} 60)\right)$ via single i.v. injection. The experimental groups covered different stages of pregnancy and varied in exposure duration and period until examination. The percentage of radioactivity recovered in rat placenta was higher at later stages of pregnancy ( $2 \%$ recovery at gestational day (GD) 18 , compared to $0.05 \%$ at GD11). On the other hand, radioactivity detected in fetuses was lower at later stages compared with earlier stages of gestation $(0.2 \%$ at GD11 and $0.04 \%$ at GD18), which can be explained by the lack of a developed placenta during early gestation [87]. Seven animal studies did not find evidence of maternal-fetal transfer of engineered NPs $[56,63,68,72,77,79,82]$.

\section{Airborne (ultra)fine particles}

Only 2 animal studies examined the maternal-fetal translocation of ambient air pollution particles [91, 92]. Black particles were observed by TEM in the maternal lungs and blood vessels of pregnant rabbits after exposure for $2 \mathrm{~h} /$ day, 5 days/week to $1 \mathrm{mg} / \mathrm{m}^{3}$ of $69 \mathrm{~nm}$ diesel 
exhaust particles (DEP) from GD3 to 27. Nonaggregated and NP-like particles were detected in the placenta, maternal blood space, trophoblastic cells, and in fetal blood [92] as well as in the fetal olfactory tissue [91]. However, the identification of these particles in the tissues was solely based on TEM observations of black particles without confirming their origin from the diesel aerosols [91, 92].

\section{In vivo maternal-fetal particle transfer in humans}

Only 2 studies examined the maternal-fetal transfer of (ultra)fine particles and NPs under real-life exposure conditions [1, 93] (Table 4). Bové et al. performed a study on a subset of term placentae from 20 healthy, non-smoking mother-newborn pairs enrolled within the Belgian ENVIRONAGE (ENVIRonmental influence $O N$ early AGEing) birth cohort [94]. Ambient black carbon (BC) particles were found in all screened placentae, and the placental $\mathrm{BC}$ load was positively associated with the mothers' residential $\mathrm{BC}$ exposure during pregnancy. The average (SD) placental BC load was $0.95 \times 10^{4}(0.66 \times$ $\left.10^{4}\right)$ and $2.09 \times 10^{4}\left(0.90 \times 10^{4}\right)$ particles per $\mathrm{mm}^{3}$ for low- and high-exposed mothers, respectively [1]. RaiaBarjat et al. assessed NP crossing over the human placenta by investigating the NP loading in amniotic fluids collected from 100 pregnant women. A high number of pregnant women with a substantial concentration of the essential trace elements iron $(\mathrm{Fe})$, copper $(\mathrm{Cu})$, and zinc $(\mathrm{Zn})$ in the nano/ion fraction was observed. In contrast, the prevalence of women with a substantial concentration of aluminum (Al), silver (Ag), beryllium (Be), cobalt $(\mathrm{Co})$, chromium $(\mathrm{Cr})$, nickel $(\mathrm{Ni})$, silicon $(\mathrm{Si})$, titanium (Ti), and tungsten (W), was relatively low (i.e., under 20\%). Nonetheless, the authors acknowledged that this does not necessarily indicate the presence of NPs since the used technique, ICP-OES, is not able to discriminate NPs from ions [93].

\section{Analytical methods to visualize and quantify maternal- fetal particle transfer}

A variety of analytical methods were used to quantify (i.e., (semi-)quantitative techniques) and/or visualize (i.e., qualitative techniques) the gestational transfer of particles by their identification in relevant tissues (e.g., placental or fetal tissue). Included studies based their results on (semi-)quantitative detection techniques $(N=$ $33)$, qualitative methods $(N=11)$, or a combination of both $(N=29)$. In total, 26 different techniques were used in the studies discussed in this review, as summarized in Table 5.

\section{Qualitative techniques}

Qualitative microscopy-based methods employed in the discussed studies included bright-field light, fluorescence, and confocal microscopy as well as transmission and scanning electron microscopy (TEM and SEM), and X-ray microscopy. The most frequently used qualitative technique was TEM $(N=22)$. Analytical tools, such as energy-dispersive X-ray spectroscopy (EDX) or Raman spectroscopy, can be coupled to electron microscopes for additional elemental composition analysis [45, 47, 75, 80, 93]. For example, Takeda et al. used field emission-type SEM (FE-SEM)/EDX to show the transfer of nanosized $\mathrm{TiO}_{2}$ from pregnant mice into the brain and testis of their offspring [80]. Autometallography, a histochemical technique based on silver enhancement, is also used to allow light and electron microscopic visualization of metallic NPs in biological tissues and cells $(N=4)$. Using TEM and silver enhancement, 10 and $15 \mathrm{~nm}$ Au PEGylated NPs could be visualized in the trophoblastic cell layer of the placenta after 6 $h$ of re-circulating perfusion, yet no particles were quantified in the fetal circulation [23].

\section{Quantitative techniques}

One of the included human studies on maternal-fetal particle transfer employed a novel detection technique based on the white-light generation by carbonaceous particles under near-infrared femtosecond pulsed illumination [1, 105]. This label-free confocal microscopic technique showed the presence of $\mathrm{BC}$ particles originating from ambient exposure at the fetal side of the human placenta [1]. Label-free detection of NPs in cells and tissues is not straightforward and, therefore, NPs are often labeled using fluorophores, radiolabels, or contrast agents. For quantitative visualization of non-fluorescent NPs in biological systems, fluorescent labeling (e.g., using fluorescein isothiocyanate [71] or rhodamine [24, 25]) can be employed followed by fluorescence detection methods. Melnik et al. used the radioactive silver isotope

${ }^{110 \mathrm{~m}} \mathrm{Ag}$ to label and track PVP-stabilized $34.9 \mathrm{~nm} \mathrm{Ag}$ NPs with gamma spectrometry, showing their accumulation in placental and fetal tissue following oral administration to pregnant mice on GD20 [53]. Moreover, Sweeney et al. functionalized mesoporous $\mathrm{SiO}_{2}$ NPs with gadolinium oxide (i.e., magnetic resonance imaging (MRI) contrast agent) and trifluoropropyl groups (i.e., ultrasound contrast agent) to allow multimodal imaging of silica NPs in pregnant mice. A time-dependent transfer was observed as $\mathrm{SiO}_{2} \mathrm{NPs}$ were only detected in the pups following maternal i.v. injection during early gestation (GD9) and not late gestation (GD14) [71]. Other quantitative analysis methods are mainly based on elemental analysis. Inductively coupled plasma (ICP) techniques, including ICP-optical emission spectroscopy (OES) and ICP-mass spectrometry (MS), are powerful tools for the detection and analysis of trace elements in homogenized tissue samples. ICP-MS, or a variant of it 


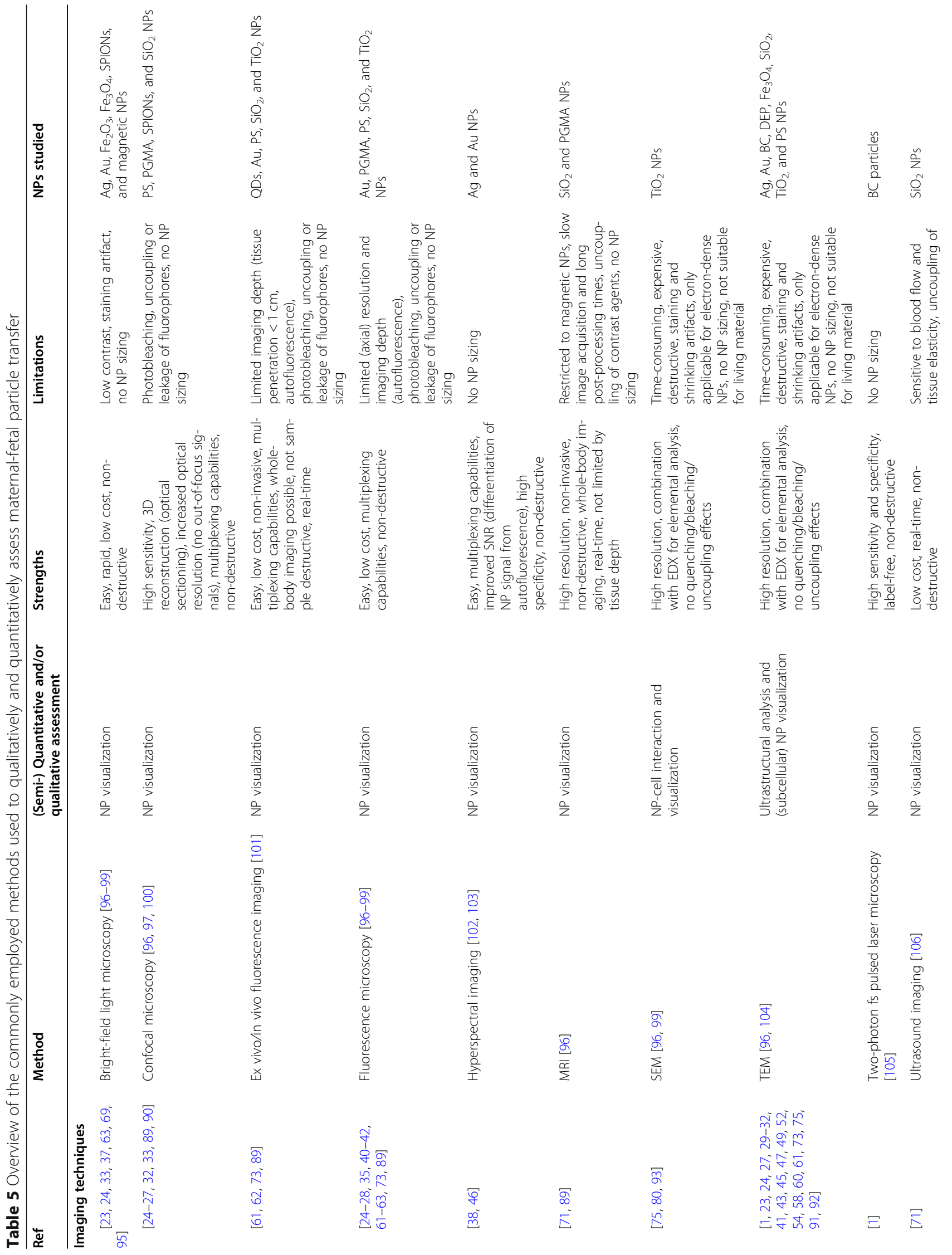




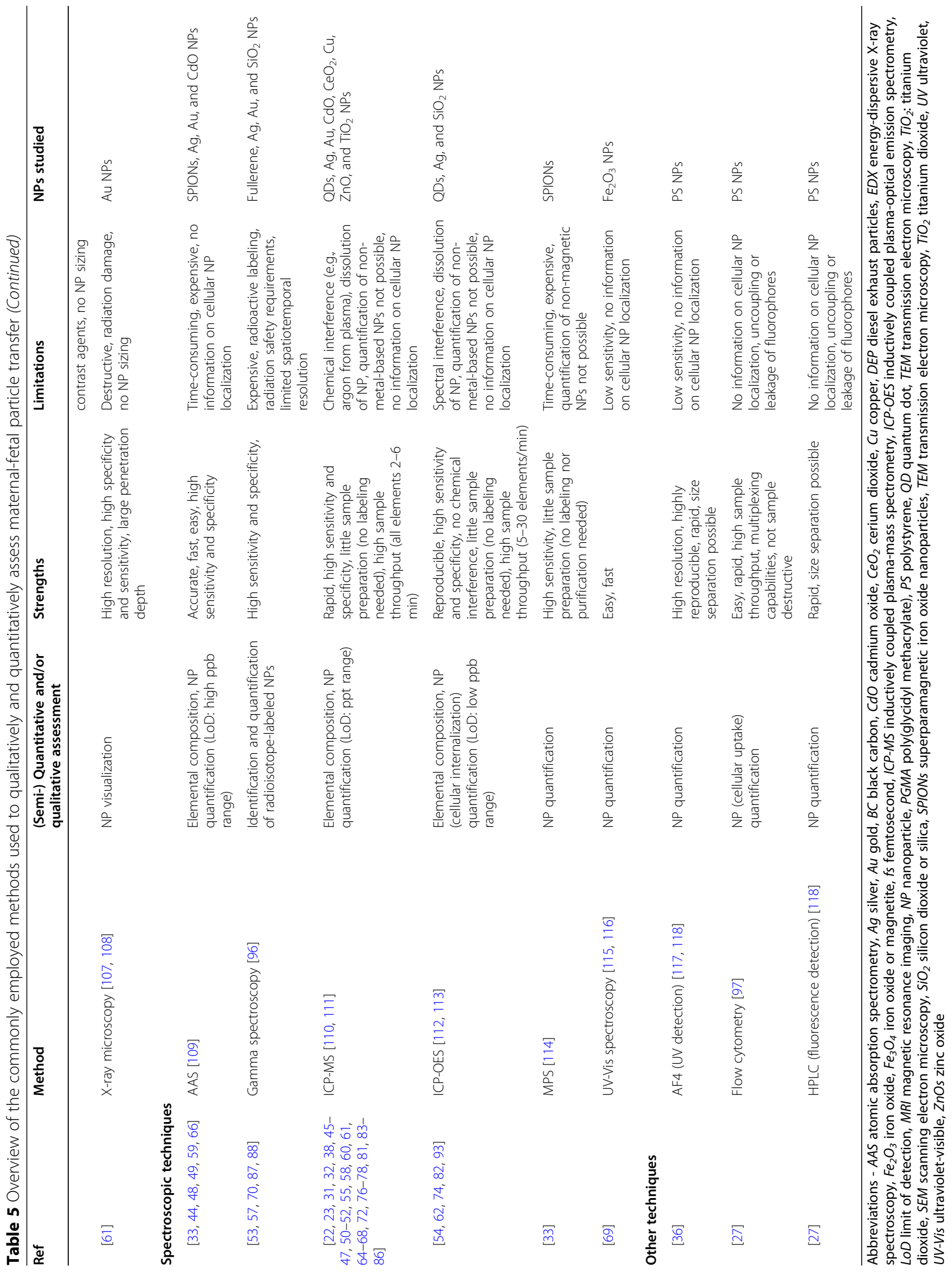


(i.e., single particle, sector field, and laser ablation ICPMS), was the most frequently used quantitative technique $(N=29)$ among the included studies. In addition, 6 of the included studies used atomic absorption spectrometry (AAS) as elemental analysis tool for detection of metallic NPs in maternal-fetal tissue [33, 44, 48, 49, $59,66]$.

\section{Combination of qualitative and quantitative techniques}

In total, 29 included studies combined quantitative and qualitative methods to gain complementary insights on the maternal-fetal transfer of NPs. For example, Ho et al. combined findings from quantitative (i.e., magnetic resonance imaging and fluorometry) and qualitative assessments (i.e., fluorescence and confocal imaging) to determine the biodistribution of cationic and anionic multimodal (i.e., fluorescent and paramagnetic) polymeric PGMA NPs in a pregnant rat model at different stages of gestation. While the quantitative methods were unable to unambiguously determine tissue uptake, confocal microscopy confirmed a differential charge-based accumulation of the NPs in the rat placenta [89]. The time-dependent transfer of SPIONs with a differential surface charge through a BeWo/pericyte co-culture was measured by magnetic particle spectroscopy and confirmed by AAS. As previously observed, neutral and negatively charged iron oxide NPs were able to pass the cell layer, whereas positively charged NPs primarily interact with the BeWo cells [33].

\section{Discussion}

\section{Placenta models used to study maternal-fetal NP translocation}

As visualized in Fig. 2a, only 2 included studies examined the transplacental passage of (ultra)fine particles or NPs in a human population under real-life exposure conditions $[1,93]$. The majority of the cited studies investigated maternal-fetal particle transfer and distribution in animal models, hence, in biological systems under controlled conditions. Mainly rodents (i.e., mice and rats) were used as animal model (Fig. 3a). Both rodents and rabbits are easy to breed and handle and their small size facilitates large scale/high throughput studies, making them cost-efficient models [119, 120]. However, placentation differs between species [121]. To compare data on transplacental NP transfer, it is necessary to understand both the physiological and anatomical differences between humans and the employed animal models [122]. Humans, rodents, and lagomorphs (rabbits) all share a discoid, hemochorial placenta, denoting that maternal blood comes in direct contact with fetal trophoblastic tissue. More specifically, hemomonochorial (human at term), hemodichorial (rabbit and human in their first trimester), and hemotrichorial (rat and mouse) placentae, with one, two, and three trophoblastic epithelial layers separating maternal and fetal blood, respectively [121]. Rodents are the most widely used animal model in developmental toxicology, yet there are structural differences between rodent and human placentae. Rodents (i) reach their definitive placental structure in a later stage, (ii) have less invasive trophoblast cells, and (iii) have a labyrinthine as opposed to a villous organization in human placentae [123, 124]. Rabbit placentae also have a labyrinthine structure, yet they are hemochorial with two trophoblast layers, a syncytium and a cytotrophoblast layer, which more closely resembles the human placenta. Moreover, critical exposure windows can be defined more precisely in rabbits as ovulation is induced by mating, resulting in the exact timing of fertilization and pregnancy stages. Rabbit placentae appear to resemble more the human placentae than that of rodents. Therefore, rabbits are considered the preferable animal model to study gestational particle exposure [120, 125]. Keeping in mind that the placenta is the most species-specific mammalian organ, various human model systems have been developed to mimic the in vivo situation in pregnant women as closely as possible.

Ex vivo perfusion of human term placentae is used as a surrogate to study the transplacental transport of NPs. It is considered as the "gold standard" among currently available translocation models as it preserves the structural complexity of a full-term placenta and resembles its dynamic environment, enabling to study ex vivo transplacental NP passage without harming the mother and/or fetus [126]. Nonetheless, perfusion studies (i) predominantly use full-term placentae and, hence, do not allow to estimate NP transfer during earlier and more vulnerable stages of pregnancy, (ii) are limited to a few hours $(4-8 \mathrm{~h})$ of perfusion due to tissue degradation, which is insufficient to observe chronic effects, (iii) have a low success rate of perfusion (i.e., 30\%), and (iv) are time-consuming $[126,127]$.

To overcome the aforementioned limitations, in vitro models using human cell cultures (primary cytotrophoblasts or choriocarcinoma cell lines) are attractive as they allow high-throughput testing of transplacental transfer of various NPs. However, models like the commonly employed BeWo b30 Transwell model also have their limitations [128]. In vitro placental transfer models do not fully resemble the physiological structure of the in vivo placenta as they lack anatomical integrity and blood flow. Moreover, monolayers form a simplified placental barrier. Co-cultures, on the other hand, attempt to more closely mimic the complex in vivo placenta that constitutes multiple cell layers (e.g., trophoblast and endothelial cell layer) across which particles have to be transported and where cell-cell interactions among 
various cell types can happen $[129,130]$. In this regard, Muoth et al. used a 3D co-culture microtissue model to more closely resemble the human placental structure, and to study Au NP uptake and penetration in an organotypic environment. Higher uptake and deeper penetration were observed for the smaller carboxylated $\mathrm{Au}$ NPs in comparison to the larger PEGylated Au NPs [32]. Interestingly, a lower degree of NP transport was observed across co-culture placental models compared to monolayer cultures. For instance, Cartwright et al. exposed a BeWo b30 monolayer to PS NPs with sizes up to $100 \mathrm{~nm}$ and was able to detect those particles in the basal compartment after $24 \mathrm{~h}$ of exposure [26]. Correspondingly, Aengenheister et al. exposed a BeWo b30/ HPEC-A2 co-culture to PS NPs with particle sizes up to $70 \mathrm{~nm}$ under similar conditions and found only low amounts of $49 \mathrm{~nm}$ PS NPs and no $70 \mathrm{~nm}$ PS NPs in the basal compartment after $24 \mathrm{~h}$ of exposure [35]. Additionally, Au NPs $( \pm 14 \mathrm{~nm})$ were able to transport across BeWo b30 and HVMF monolayers, while they barely passed the co-culture of both cell types [32]. Nonetheless, most in vitro models lack a physiological microenvironment as they are exposed to NPs under static conditions.

Although a variety of placental models are currently available, the preconditions of each model should be taken into consideration depending on the research objective. High-throughput in vitro transfer models are useful to pre-screen a variety of NPs and to provide mechanistic insights, yet, further improvements (e.g., microfluidic approaches to develop a dynamic model) are needed to enhance their predictive value. Ex vivo placental perfusion studies provide transfer data with high in vivo relevance, at least for term pregnancy. On the other hand, exposure of pregnant animal models can provide important insights on the biodistribution of NPs in a living organism, including potential translocation to the fetus. Nevertheless, data extrapolation from animals to humans remains challenging as the placenta is the most species-specific mammalian organ. Despite technical challenges and ethical constraints, term human placentae form the ideal model to study transplacental NP transfer.

\section{Evidence of maternal-fetal NPs translocation}

The majority of the cited studies observed transplacental transfer of (ultra)fine particles and NPs (Fig. 2c). This supports the finding that the placenta is not an impenetrable barrier, as already confirmed for other xenobiotics such as drugs and alcohol [131]. In animal models, transplacental passage has been reported for Ag NPs [47-54], $\mathrm{Al}_{2} \mathrm{O}_{3}$ NPs [44], $\mathrm{Au}$ NPs [57, 59-61], $\mathrm{CeO}_{2}$ NPs [67], DEP [91], QDs [62], $\mathrm{SiO}_{2}$ NPs [70, 71, 73, 74], $\mathrm{TiO}_{2}$ NPs [73, 75, 76, 78, 80, 81], ZnO NPs [83-85],
$\mathrm{ZrO}_{2} \mathrm{NPs}$ [86], $\mathrm{Fe}_{2} \mathrm{O}_{3}$ NPs [69], C60 fullerenes [87], PGMA NPs [89], and PS NPs [27]. Among these particles, only Ag NPs [37], Au NPs [31, 38], and PS NPs [40-43] showed transplacental transfer in an ex vivo perfusion model, whereas $\mathrm{SiO}_{2} \mathrm{NPs}$ [25] and $\mathrm{TiO}_{2} \mathrm{NPs}$ [34] were retained in the placental tissue. Similarly, $\mathrm{Ag}$ NPs [22], Au NPs [31, 32], iron oxide NPs [24, 33], $\mathrm{SiO}_{2}$ NPs [24], and PS NPs [35] were shown to cross the in vitro placental barrier. Solely 22 studies based their findings on visual confirmation of particle presence or a significant difference in NP content from the control group in the fetal compartment/tissue. Moreover, 22 studies substantiated their evidence for maternal-fetal NP translocation by determining the limit of detection, i.e., values exceeding the empirically defined size and/or concentration limits. Nonetheless, other studies reported contradictory results and report the absence of NP placental transfer or fetal uptake of Au NPs [56], $\mathrm{Cu}$ NPs [68], Pt NPs [72], $\mathrm{TiO}_{2}$ NPs [77, 79], QDs [63], and $\mathrm{ZnO}$ NPs [82]. Yet, this may be due to inadequate size and concentration detection limits of the employed techniques, as discussed in the section "advantages and disadvantages of methods used to assess maternal-fetal NP translocation".

\section{Factors that influence maternal-fetal translocation}

Various studies showed the influence of different factors on maternal-fetal particle translocation, including particle size, particle material, dose, particle dissolution, and surface composition, as well as NP administration route and the gestational stage of the study model.

First, the effect of particle size on transplacental transfer was addressed by 6 included studies [27, 55, 57, 62, $73,85]$. For instance, Yamashita et al. i.v. administered 70, 300, or $1000 \mathrm{~nm} \mathrm{SiO}$ 2 particles to pregnant mice and concluded that only the $70 \mathrm{~nm}$ particles could reach the placentae, fetal liver, and fetal brain tissue [73]. Similar size-dependent transplacental transfer was observed for PS NPs in the ex vivo placental perfusion [40, 42, 43] and in vitro $[26,27,35]$ studies. Different sizedependent mechanisms of placental NP exchange have been proposed, including passive and facilitated diffusion via transtrophoblastic channels (i.e., canaliculi) and active transport (e.g., receptor-mediated endocytosis), yet mechanistic insights on transplacental NP transfer remain scarce [39]. Despite the use of various placental transporter inhibitors, no major influence on the translocation of $50 \mathrm{~nm}$ PS NPs in the in vitro BeWo transfer model was observed, which indicates preferential NP translocation by passive diffusion [28]. In contrast, bidirectional ex vivo placental perfusion studies showed an increased fetal to maternal transfer of $50 \mathrm{~nm}$ PS NPs suggesting an active, energy-dependent transplacental transport mechanism for PS NPs [41]. Additionally, 
upregulation of clathrin- and caveolin-mediated endocytosis was observed following i.v. administration of 20 and $50 \mathrm{~nm} \mathrm{Au} \mathrm{NPs} \mathrm{[55]} \mathrm{and} \mathrm{oral} \mathrm{administration} \mathrm{of} 16$ $\mathrm{nm} \mathrm{ZrO}_{2}$ [86] in pregnant mice. Noteworthy, the particle cut-off size, above which no transplacental particle translocation is observed, appears to be influenced by the particle material. Aengenheister et al. showed the in vitro transplacental transfer of $50 \mathrm{~nm}$ PS [35] but not 4-8 nm $\mathrm{TiO}_{2}$ NPs [34] across a $\mathrm{BeWo} / \mathrm{HPEC}$ co-culture. The study also showed that the $4-8 \mathrm{~nm} \mathrm{TiO}_{2} \mathrm{NPs}$ were not able to cross the placenta in an ex vivo perfusion model [34], whereas PS NPs up to $240 \mathrm{~nm}$ have been shown to reach the fetal circuit [43] in a similar perfusion study. In agreement, in pregnant mice, $5 \mathrm{~nm} \mathrm{TiO}_{2}$ did not cross the placenta [79], while PS NPs up to 500 $\mathrm{nm}$ could be observed in various organs of fetuses [27]. Moreover, Kloet et al. observed a difference in translocation behavior of PS NPs with a similar size and surface charge but acquired from different manufactures [28]. This reflects the difficulty to compare results between, and even within, studies due to variations in NP characteristics on top of differences in the employed detection technique.

Second, numerous studies reported that the surface composition of the particles has a tremendous influence on their in vivo translocation [22, 24, 31-34, 37, 41, 42, 61, 62, 69, 74, 89, 95, 96]. Accordingly, Yang et al. exploited three types of surface modifications to assess the effect of surface functionality on maternal-placentalfetal biodistribution of $13 \mathrm{~nm}$ Au NPs in fetuses of mice; coating with (i) endogenous proteins (i.e., ferritin) for optimal biocompatibility, (ii) stealth groups (i.e., PEG polymer chains) to increase circulation time by avoiding recognition and phagocytosis by the mononuclear phagocytic system, and by reducing NP-cell and NPprotein interactions, and (iii) stabilizing anionic material (i.e., citrate) to explore the effects of negative charge on placental and fetal distribution. Substantially less uptake of $13 \mathrm{~nm}$ citrate-capped Au NPs in fetal tissues has been found compared to ferritin-modified or PEGylated $\mathrm{Au}$ NPs with an identical size [61]. A similar effect of surface charge on the transplacental crossing of metal oxide NPs was demonstrated by coating $14 \mathrm{~nm} \mathrm{Fe}_{2} \mathrm{O}_{3}$ NPs with either negatively charged PAA-groups or positively charged PEI-groups. Pregnant mice intraperitoneally exposed to $10 \mathrm{mg} / \mathrm{kg} \mathrm{Fe}_{2} \mathrm{O}_{3}$-PEI for eight consecutive days (i.e., GD9 to 16) had significantly increased iron levels in their placentae and the livers of their offspring compared to mice exposed to $\mathrm{Fe}_{2} \mathrm{O}_{3}$-PAA [69]. In general, an increased transplacental transfer for PEGylated NPs was observed among the included studies, while carboxylated NPs were mainly retained inside placental tissue [31, 37, 41, 42]. In accordance, Aengenheister et al. showed that both carboxylated and PEGylated Au NPs crossed the placental co-culture in low amounts. Despite the higher cellular uptake of carboxylated Au NPs, increased translocation was observed for PEGylated Au NPs. In contrast, only PEGylated particles reached the fetal circulation in the dynamic ex vivo placental perfusion model [31]. Possible explanations given by the authors for the absence of carboxylated particles in the fetal circulation were: (i) the agglomeration behavior of carboxylated Au NPs, and (ii) the non-specific adherence of carboxylated $\mathrm{Au}$ NPs to the perfusion system, both markedly reducing the cellular available dose. In all cases, the carboxylated particles were larger than the PEGylated NPs, which can partially explain the reduced transfer.

Third, another factor with considerable influence on maternal-fetal NP transfer is particle dose as discussed in 9 included studies [24, 45, 48, 62, 66, 76, 79, 81, 86]. By increasing the dosage of i.v. injected 3mercaptopropionic acid (MPA)-coated QDs in pregnant mice, Chu et al. observed a corresponding increase in $\mathrm{Cd}$ concentration in the pups [62]. Similar results were observed for $\mathrm{TiO}_{2}$ NPs $[76,81]$ and $\mathrm{ZrO}_{2}$ NPs [86] in a pregnant mouse model. However, a lack of doseresponse was observed for CdO [66] NPs and Ag NPs $[45,48]$, possibly because the tissue saturation limit was not reached by the administered NPs, as suggested by Austin et al. $[45,48]$. In general, NP uptake and translocation do not only depend on their physicochemical properties, surface modification, and particle concentration but also on particle dissolution. The latter is an important property to consider because it alters the particle presence. Accordingly, translocation may be observed which cannot only be attributed to intact NPs (e.g., Ag NPs, CdO NPs, and ZnO NPs), but also released ions, precipitates, or a combination. NP dissolution has been reported by 7 [22, 37, 45, 47, 48, 66, 85] of the included studies yet only 2 distinguished between the translocation and uptake of actual particles or dissolved Ag in an in vitro placental barrier model [22] and ex vivo placental perfusion model [37]. Both studies showed a favorable transplacental transport of ionic over particulate Ag and highlighted the need to consider the uptake of $\mathrm{Ag}$ ions and/or dissolution of Ag NPs in the cellular barrier or tissue followed by re-precipitation to Ag NPs in the basolateral compartment or fetal circulation, respectively. On the other hand, Wang et al. showed that the integrity of $\mathrm{ZrO}_{2}$ NPs was not altered upon encountering biological barriers in a pregnant mouse model as the ionic $\mathrm{Zr}$ content was fewer than $1 \%$ after incubation of $\mathrm{ZrO}_{2} \mathrm{NPs}$ with water or artificial gastric fluid for $5 \mathrm{~h}$ [86].

Fourth, the administration route in in vivo animal studies is an important factor influencing particle translocation. As depicted in Fig. 3b, inhalation exposure 
$(N=6)$ remains fairly understudied in gestational translocation studies despite being the main entry route in environmental and occupational settings. Among the included studies, i.v. administration $(N=27)$ is mainly used as route of exposure. i.v. NP injection allows to control the systemically available dose as NPs do not have to cross primary biological barriers (e.g., lung or intestinal epithelium), which would result in limited transfer across the placenta and thus unfeasible detection limits that restrain the visualization and quantification of NPs in embryonic/fetal tissue [132]. However, the data from i.v. route studies cannot directly be extrapolated to the real-life scenario of inhalation exposure due to differences in the systemic distribution pattern [133]. For example, the differences in the overall distribution patterns might be determined by the different protein coronae that arise when particles come into contact with bronchoalveolar fluid compared to plasma [134-136].

Fifth, the previously highlighted interspecies differences are further complicated by dissimilarities in placental anatomy and physiology between the various stages of pregnancy, making it necessary to focus on a critical exposure period in animals that reflects an equivalent stage in human development [137]. Alignment of rodent and lagomorph reproductive timelines with that of humans is based on Theiler (mouse) [138], Witschi (rat) [139], Edwards (rabbit) [140], and Carnegie (human) [141] stages of development. The included studies employed various gestational windows of NP exposure ranging from exposure during early or late gestation $[60,67,70,71,74,85,89]$ to continuous exposure during the whole pregnancy $[1,52,68,72,76,81,92,93]$ to assess the time-dependence of transplacental particle transfer. In this regard, polymeric NPs accumulated in different compartments of the rat conceptus during early (GD10), but not late (GD20) gestation, consistent with the lack of a developed placenta during early gestation [89]. Similarly, Wang et al. reported a higher translocation of $\mathrm{ZrO}_{2}$ NPs to the mouse placenta, fetal brain, and fetal liver following oral exposure during early stages of pregnancy (i.e., GD9-11 and GD13-15) compared to NP administration later in gestation (i.e., GD16-18) [86]. On the other hand, Pietroiusti et al. detected 25 and $60 \mathrm{~nm} \mathrm{SiO} \mathrm{SPS}_{2} \mathrm{NP}$ in the mouse conceptus after i.v. administration at GD5.5 and GD12.5. At later stages (GD16.5), when the placenta acquired higher permeability, larger $115 \mathrm{~nm} \mathrm{SiO}_{2} \mathrm{NPs}$ were able to reach the mouse conceptus [74].

\section{Methods used to assess maternal-fetal NP translocation}

Studies on gestational NP biodistribution demand highly sensitive visualization and quantification methods because the accurate detection of the fetoplacental accumulation of nanomaterials at very low levels is required.
The uptake of particulates into the systemic circulation is limited and often amounts less than a few percent of the total administered dose [142]. For example, Hesler et al. showed a lack of transport of $50 \mathrm{~nm}$ carboxylated PS NPs across a placental co-culture using an asymmetrical flow field-flow fractionation (AF4) system. Still, they recognize that it cannot be excluded that a small number of particles, below the detection limit of the AF4 system, could have been translocated [36]. This detection limit is possibly confirmed by other studies that were able to show a size-dependent translocation of similar PS NPs in mice [27] as well as in an ex vivo placental perfusion model $[41,42]$.

As summarized in Table 5, a multitude of imaging approaches was used to visualize NPs in an in vitro, ex vivo, and in vivo context. Some included studies investigated maternal-fetal NP distribution at the wholebody level by using magnetic resonance imaging [71, 89], in vivo/ex vivo fluorescence imaging [61, 62, 73, 89], or radiolabeling techniques [53, 57, 70, 87]; whereas other reports focused on the subcellular localization of NPs by exploiting transmission [23, 24, 27, 29-32, 41, $43,45,47,49,52,54,57,58,60,61,73,75,91,92]$ or scanning electron microscopy [75, 80, 93]. Fluorescence microscopy is generally the method-of-choice to monitor the cellular and tissue-level distribution of fluorescent NPs [143]. However, visualization of fluorescent NPs, even with high-resolution confocal microscopy, is limited because of their sizes (typically being between 1 and $100 \mathrm{~nm}$ ), which is below the Abbe's diffraction limit of $\sim 250 \mathrm{~nm}$. An additional consideration when using fluorescent NPs is dye leakage [144]. Stable incorporation of dyes within the NPs is a prerequisite as the fluorescence from leaked dyes may cause wrong interpretation of NP biodistribution [145]. Accordingly, the in vitro stability of the fluorescent dye in different solutions, including perfusion medium $[42,43]$, and phosphate buffered saline [73], was measured in some of the included studies to exclude false-positive results. Moreover, the detection of fluorescent NPs may be hindered by the autofluorescence of the biological samples, which hampers the visualization of small aggregates [143]. Kenesei et al. employed spectral imaging fluorescence microscopy to distinguish fluorescence, originating from the i.v. injected carboxylated or PEGylated PS NPs, from tissue autofluorescence in mice. The study revealed no placental penetration but retention of PS NPs by the reticuloendothelial system regardless of surface functionalization [90]. In general, fluorescence microscopic techniques are hampered by the risk of sample photobleaching combined with limited particle size detection and the necessity to fluorescently couple the NP under study. The latter is facilitated in the case of (i) QDs [62-65], which possess inherent fluorescence, or (ii) carbonaceous 
particles, which generate white-light under femtosecond pulsed laser illumination $[1,105]$. Such label-free detection methods allow the direct analysis of maternal-fetal NP uptake. Chu et al. used fluorescence imaging to investigate whether intact QDs can transfer across the rodent placenta to reach the fetus. Penetration of the placenta by intact QDs was hard to demonstrate using in vivo fluorescence imaging, possibly due to a low fetal concentration combined with a reduction in fluorescence intensity due to background tissue-endogenous fluorescence (i.e., autofluorescence). Nonetheless, increased Cd levels, originating from QDs, were measured in mouse fetuses and pups using ICP-OES [62]. Another study indicated that the $\mathrm{Cd}$ ions originating from $\mathrm{CdO}$ NPs, instead of the particles themselves, were able to translocate across the placenta of a pregnant mice model [66]. In agreement, favorable transport of ionic silver over pristine Ag NPs was observed across the in vitro placental cell layer and in the ex vivo placental perfusion model [22, 37]. High concentrations of dissolved ions may overestimate the concentration of materials present in nanoparticle form when using chemical analysisbased methods (e.g., ICP-OES and ICP-MS) that measure the total elemental concentration in a sample [146]. In contrast, single-particle ICP-MS (spICP-MS) allows determination of the elemental composition of single particles and provides information on the NP size distribution. Furthermore, spICP-MS can distinguish between dissolved and nanoparticulate forms of a certain material [147]. In this regard, Abdelkhaliq et al. showed the transport of ionic silver and Ag NPs across an in vitro BeWo b30 model using ICP-MS and spICP-MS, respectively [22]. In addition, separation techniques are often used to remove target particles from interfering matrix components to meet the quantification limits of the detection methods. Accordingly, chromatography-based techniques such as field-flow fractionation and highperformance liquid chromatography (HPLC) are used for high-resolution sizing and separation of a wide range of diverse particles $[148,149]$. Coupling of the chromatographic instruments with other spectroscopic techniques, such as light scattering or light absorption methods, can be used to enhance the characterization power as it allows the physicochemical characterization and elemental analysis of the size-separated particles [150]. In this regard, Hesler et al. used an AF4-UV method for size analysis and quantification of carboxylated PS NPs across an in vitro placental co-culture [36].

To summarize, quantification and reliable detection of NPs in maternal-fetal tissue remain one of the main challenges in transplacental transfer studies, especially under realistic exposure conditions where transfer rates are expected to be lower. Quantification of maternalfetal NP uptake is often achieved at the cost of spatial resolution, whereas intracellular NP localization is often qualitatively defined. Hence, techniques are best combined to gain complementary and profound insights in transplacental particle transfer. Moreover, progress should be made towards standardization and validation of methods used to detect (ultra)fine particles and NPs with high specificity to ensure reliable detection of the particles of interest. Such implementation of standardized protocols would facilitate the comparison between different studies on particle exposure and the assessment of associated health and safety risks.

\section{Conclusion and future directions}

Exposure to (ultra)fine particles and NPs in daily life is unavoidable, and this is no different for pregnant women. This systematic review summarizes the evidence that particles can bypass the placenta as observed in (i) in vitro monolayers and co-cultures of different placental cells (e.g., trophoblasts, fibroblastic cells, and endothelial cells), (ii) ex vivo placental perfusion models, and (iii) in vivo rodent and rabbit models and humans. Almost all types of particles tested, ambient or engineered, seemed to be able to reach and/or cross the maternalfetal barrier, even if merely in trace amounts. Transplacental particle transport is affected by the particle size, particle material, dose, particle dissolution, and surface modification, as well as the NP administration route and gestational stage of the employed model. Results on placental NP transfer must be interpreted with care seeing differences in the species origin (i.e., rodent, rabbit, or human) and complexity (i.e., in vitro, ex vivo, or in vivo) of the applied model as well as in particle properties and routes of NP exposure/administration. To obtain substantial and complementary results on developmental toxicity following prenatal exposure, it will be essential to test realistic doses (extrapolated from populationbased studies) and exposure routes. The number of studies on transplacental NP transfer remains limited. More studies on the topic are paramount and in particular on inhalation exposure since this is the primary route of environmental and occupational exposure and largely understudied.

Moreover, to date, little is known about the kinetics and bioavailability of NPs as no simple nor standardized method for NP detection and/or quantification in biological settings is available. This urges the need to come up with standardized protocols and to develop state-ofthe-art methods to accurately detect and quantify the fetoplacental accumulation of low particle levels in tissues, such as in fetal samples.

To conclude, further research on particle uptake, accumulation, and translocation at the placenta is indispensable to predict potential fetal exposure and adverse health effects during fetal development and later in life. 


\section{Supplementary Information}

The online version contains supplementary material available at https://doi. org/10.1186/s12989-020-00386-8.

Additional file 1. Protocol.

Additional file 2. Review methods description.

\section{Abbreviations}

${ }^{110 \mathrm{~m}} \mathrm{Ag}$ : Silver-110 m radioisotope; ${ }^{14} \mathrm{C}$ : Carbon-14 or radiocarbon; 3A-subE: Human SV40 transformed 3A-Sub-E trophoblast cell line; 3D: Threedimensional; AAS: Atomic absorption spectrometry; AF4: Asymmetrical flow field-flow fractionation system; Al: Aluminum; $\mathrm{Al}_{2} \mathrm{O}_{3}$ : Aluminum oxide or alumina; Ag: Silver; $\mathrm{Ag}_{2} \mathrm{~S}$ : Silver sulfide; AMG: Autometallography; APTES: $3-$ aminopropyl triethoxydsilane; Au: Gold; Be: Beryllium; BC: Black carbon; BeWo (b30): Human placental choriocarcinoma cell line; C60: Fullerene; Cd: Cadmium; CdO: Cadmium oxide; CdS: Cadmium sulfide; CdTe: Cadmium telluride; CdSe: Cadmium selenide; $\mathrm{CeO}_{2}$ : Cerium dioxide; CMX: Carboxymethyl dextran; Co: Cobalt; CO: Carbon monoxide; COOH: Carboxyl; COONa: Carboxyl; Cr: Chromium; Cu: Copper; DEP: Diesel exhaust particles; EDX: Energy-dispersive X-ray spectroscopy; ENVI RONAGE: ENVIRonmental influence ON early AGEing; $\mathrm{Fe}_{2} \mathrm{O}_{3}$ : Iron oxide; $\mathrm{Fe}_{3} \mathrm{O}_{4}$ : Iron oxide or magnetite; FE-SEM/EDX: Field emission-type scanning electron microscopy/energy-dispersive X-ray spectroscopy; fs: Femtosecond; GD: Gestational day; GIT: Gastrointestinal tract; h: Hours; hPC-PL: Primary human placental pericytes; HPEC-A2: SV40-transformed microvascular human placental venous endothelial cells; HPLC: High-performance liquid chromatography; HVMF: Human villous mesenchymal fibroblasts; ICP: Inductively coupled plasma; ICP-MS: Inductively coupled plasma-mass spectrometry; ICP-OES: Inductively coupled plasma-optical emission spectrometry; i.p.: Intraperitoneal; i.v.: Intravenous; kg: Kilogram; LA-ICP-MS: Laser ablation-inductively coupled plasma-mass spectrometry; $\mathrm{m}^{3}$ : Cubic meter; MBq: Megabecquerel; MeSH: Medical subject headings; mg: Milligram; mL: Milliliter; MMSNPs: Magnetic mesoporous silica nanoparticles; MPA: 3mercaptopropionic acid; MPS: Magnetic particle spectroscopy; MRI: Magnetic resonance imaging; MS: Mass spectrometry; $\mu \mathrm{g}$ : Microgram; $\mu \mathrm{m}$ : Micrometer; Na: Sodium; n.d.: Not defined; ng: Nanogram; Ni: Nickel; nm: Nanometer; nmol: Nanomolar; $\mathrm{NO}_{2}$ : Nitrogen dioxide; NP: Nanoparticle; $\mathrm{O}_{3}$ : Ozone; OES: Optical emission spectroscopy; PAA: Poly(acrylic acid);

PEG: Poly(ethylene glycol); PEl: Poly(ethyleneimine); PGMA: Poly(glycidyl methacrylate); $\mathrm{PM}_{2.5}$ : Particulate matter smaller than $2.5 \mu \mathrm{m}$ in diameter; PND: Postnatal day; PRISMA: Preferred Reporting Items for Systematic reviews and Meta-Analyses; PS: Polystyrene; Pt: Platinum; PVP: Polyvinylpyrrolidone; QD: Quantum dot; S.c.: Subcutaneous; SD: Standard deviation; SEM: Scanning electron microscopy; SF-ICP-MS: Sector field inductively coupled plasmamass spectrometry; Si: Silicon; $\mathrm{SiO}_{2}$ : Silicon dioxide or silica; SMPS: Scanning mobility particle sizer; $\mathrm{SO}_{2}$ : Sulfur dioxide; SPIONs: Superparamagnetic iron oxide nanoparticles; S-TPP: Sulfonated triphenylphosphine; TEM: Transmission electron microscopy; TFP: Trifluoropropyl; Ti: Titanium; $\mathrm{TiO}_{2}$ : Titanium dioxide; UV: Ultraviolet; UV-Vis: Ultraviolet-visible; W: Tungsten; ZnO: Zinc oxide; ZnS: Zinc sulfide; $\mathrm{ZrO}_{2}$ : Zirconium dioxide

\section{Acknowledgments}

Not applicable.

\section{Authors' contributions}

$E B, T S N, T V P, M A$, and HB have contributed to the definition of the scope of the review. EB and TVP identified studies, summarized all eligible papers, synthesized the findings, and drafted the manuscript. TSN, MA, and HB provided critical comments and $\mathrm{HB}$ is the guarantor of the work. All authors read, provided feedback, and approved the final manuscript.

\section{Funding}

This work was supported by the Flemish Scientific Research Foundation (FWO) funding granted to EB (1150920 N), TSN and MA (G082317N), and HB (12P6819N). The FWO had no role in the design, conduct, and preparation of the manuscript.

\section{Availability of data and materials} Not applicable.
Ethics approval and consent to participate

Not applicable.

\section{Consent for publication}

Not applicable.

\section{Competing interests}

The authors declare that they have no competing interests.

\section{Author details}

${ }^{1}$ Centre for Environmental Sciences, Hasselt University, Agoralaan Building D, 3590 Diepenbeek, Belgium. ²Department of Public Health and Primary Care, KU Leuven, Herestraat 49, Box 703, 3000 Leuven, Belgium. ${ }^{3}$ Biomedical Research Institute, Hasselt University, Agoralaan Building C, 3590 Diepenbeek, Belgium.

Received: 9 June 2020 Accepted: 20 October 2020

Published online: 02 November 2020

\section{References}

1. Bové H, Bongaerts E, Slenders E, Bijnens EM, Saenen ND, Gyselaers W, et al. Ambient black carbon particles reach the fetal side of human placenta. Nat Commun. 2019;10:3866.

2. Luyten $L$, Saenen ND, Janssen BG, Vrijens K, Plusquin M, Roels HA, et al. Air pollution and the fetal origin of disease: a systematic review of the molecular signatures of air pollution exposure in human placenta. Environ Res. 2018;166:310-23.

3. Barker DJP. Fetal origins of coronary heart disease. BMJ. 1995:171-4 Available from: https://doi.org/10.1136/bmj.311.6998.171.

4. Pedersen M, Giorgis-Allemand L, Bernard C, Aguilera I, Andersen A-MN, Ballester F, et al. Ambient air pollution and low birthweight: a European cohort study (ESCAPE). Lancet Respiratory Med. 2013:695-704 Available from: https://doi.org/10.1016/s2213-2600(13)70192-9.

5. Dadvand P, Parker J, Bell ML, Bonzini M, Brauer M, Darrow LA, et al. Materna exposure to particulate air pollution and term birth weight: a multi-country evaluation of effect and heterogeneity. Environ Health Perspect. 2013;121: 267-373.

6. Li X, Huang S, Jiao A, Yang X, Yun J, Wang Y, et al. Association between ambient fine particulate matter and preterm birth or term low birth weight: an updated systematic review and meta-analysis. Environ Pollut. 2017;227: 596-605.

7. Klepac P, Locatelli I, Korošec S, Künzli N, Kukec A. Ambient air pollution and pregnancy outcomes: a comprehensive review and identification of environmental public health challenges. Environ Res. 2018;167:144-59.

8. Lavigne E, Lima I, Hatzopoulou M, Van Ryswyk K, Decou ML, Luo W, et al. Spatial variations in ambient ultrafine particle concentrations and risk of congenital heart defects. Environ Int. 2019;130:104953.

9. Breton CV, Mack WJ, Yao J, Berhane K, Amadeus M, Lurmann F, et al. Prenatal air pollution exposure and early cardiovascular phenotypes in young adults. PLoS One. 2016;11:e0150825.

10. Bharadwaj P, Zivin JG, Mullins JT, Neidell M. Early-life exposure to the great smog of 1952 and the development of asthma. Am J Respir Crit Care Med. 2016;194:1475-82.

11. Hehua Z, Qing C, Shanyan G, Qijun W, Yuhong Z. The impact of prenatal exposure to air pollution on childhood wheezing and asthma: a systematic review. Environ Res. 2017;159:519-30.

12. Sunyer J, Dadvand P. Pre-natal brain development as a target for urban air pollution. Basic Clin Pharmacol Toxicol. 2019;125(Suppl 3):81-8.

13. Lertxundi A, Andiarena A, Martínez MD, Ayerdi M, Murcia M, Estarlich M, et al. Prenatal exposure to PM2.5 and NO2 and sex-dependent infant cognitive and motor development. Environ Res. 2019;174:114-21.

14. Nel A, Xia T, Mädler L, Li N. Toxic potential of materials at the nanolevel. Science. 2006;311:622-7.

15. Manangama G, Migault L, Audignon-Durand S, Gramond C, Zaros C, Bouvier $\mathrm{G}$, et al. Maternal occupational exposures to nanoscale particles and small for gestational age outcome in the French longitudinal study of children. Environ Int. 2019;122:322-9.

16. Moher D, Liberati A, Tetzlaff J, Altman DG, PRISMA Group. Preferred reporting items for systematic reviews and meta-analyses: the PRISMA statement. PLoS Med. 2009;6:e1000097. 
17. Keelan JA, Leong JW, Ho D, lyer KS. Therapeutic and safety considerations of nanoparticle-mediated drug delivery in pregnancy. Nanomedicine. 2015; 10:2229-47.

18. Refuerzo JS, Alexander JF, Leonard F, Leon M, Longo M, Godin B. Liposomes: a nanoscale drug carrying system to prevent indomethacin passage to the fetus in a pregnant mouse model. Am J Obstet Gynecol. 2015;212:508-e1-7.

19. Zhang B, Liang R, Zheng M, Cai L, Fan X. Surface-Functionalized Nanoparticles as Efficient Tools in Targeted Therapy of Pregnancy Complications. Int J Mol Sci. 2019;20 Available from: https://doi.org/10.3390/ ijms20153642.

20. Albekairi NA, Al-Enazy S, Ali S, Rytting E. Transport of digoxin-loaded polymeric nanoparticles across BeWo cells, an in vitro model of human placental trophoblast. Ther Deliv. 2015;6:1325-34.

21. Fournier SB, D'Errico JN, Stapleton PA. Engineered nanomaterial applications in perinatal therapeutics. Pharmacol Res. 2018;130:36-43.

22. Abdelkhaliq $\mathrm{A}$, van der Zande $\mathrm{M}$, Peters RJB, Bouwmeester $\mathrm{H}$. Combination of the BeWo b30 placental transport model and the embryonic stem cell test to assess the potential developmental toxicity of silver nanoparticles. Part Fibre Toxicol. 2020;17:11.

23. Myllynen PK, Loughran MJ, Howard CV, Sormunen R, Walsh AA, Vähäkangas $\mathrm{KH}$. Kinetics of gold nanoparticles in the human placenta. Reprod Toxicol. 2008;26:130-7

24. Correia Carreira S, Walker L, Paul K, Saunders M. The toxicity, transport and uptake of nanoparticles in the in vitro BeWo b30 placental cell barrier model used within NanoTEST. Nanotoxicology. 2015;9(Suppl 1):66-78.

25. Poulsen MS, Mose T, Maroun LL, Mathiesen L, Knudsen LE, Rytting E. Kinetics of silica nanoparticles in the human placenta. Nanotoxicology. 2015; 9(Suppl 1):79-86.

26. Cartwright L, Poulsen MS, Nielsen HM, Pojana G, Knudsen LE, Saunders M, et al. In vitro placental model optimization for nanoparticle transport studies. Int J Nanomedicine. 2012;7:497-510.

27. Huang J-P, Hsieh PCH, Chen C-Y, Wang T-Y, Chen P-C, Liu C-C, et al. Nanoparticles can cross mouse placenta and induce trophoblast apoptosis. Placenta. 2015;36:1433-41.

28. Kloet SK, Walczak AP, Louisse J, van den Berg HHJ, Bouwmeester H, Tromp P, et al. Translocation of positively and negatively charged polystyrene nanoparticles in an in vitro placental model. Toxicol in Vitro. 2015;29:1701-10.

29. Nääv Å, Erlandsson L, Isaxon C, Åsander Frostner E, Ehinger J, Sporre MK, et al. Urban PM2.5 Induces Cellular Toxicity, Hormone Dysregulation, Oxidative Damage, Inflammation, and Mitochondrial Interference in the HRT8 Trophoblast Cell Line. Front Endocrinol. 2020;11:75.

30. Erlandsson L, Lindgren R, Nääv $\AA$, Krais AM, Strandberg B, Lundh T, et al. Exposure to wood smoke particles leads to inflammation, disrupted proliferation and damage to cellular structures in a human first trimeste trophoblast cell line. Environ Pollut. 2020;264:114790.

31. Aengenheister L, Dietrich D, Sadeghpour A, Manser P, Diener L, Wichser A, et al. Gold nanoparticle distribution in advanced in vitro and ex vivo human placental barrier models. J Nanobiotechnology. 2018;16:79.

32. Muoth C, Großgarten M, Karst U, Ruiz J, Astruc D, Moya S, et al. Impact of particle size and surface modification on gold nanoparticle penetration into human placental microtissues. Nanomedicine. 2017;12:1119-33.

33. Müller EK, Gräfe C, Wiekhorst F, Bergemann C, Weidner A, Dutz S, et al. Magnetic Nanoparticles Interact and Pass an In Vitro Co-Culture BloodPlacenta Barrier Model. Nanomaterials (Basel). 2018;8 Available from: https://doi.org/10.3390/nano8020108.

34. Aengenheister $L$, Dugershaw BB, Manser $P$, Wichser A, Schoenenberger R, Wick $P$, et al. Investigating the accumulation and translocation of titanium dioxide nanoparticles with different surface modifications in static and dynamic human placental transfer models. Eur J Pharm Biopharm. 2019;142:488-97.

35. Aengenheister $L$, Keevend K, Muoth C, Schönenberger R, Diener L, Wick P, et al. An advanced human in vitro co-culture model for translocation studies across the placental barrier. Sci Rep. 2018;8:5388.

36. Hesler M, Aengenheister L, Ellinger B, Drexel R, Straskraba S, Jost C, et al. Multi-endpoint toxicological assessment of polystyrene nano- and microparticles in different biological models in vitro. Toxicol in Vitro. 2019; 61:104610

37. Vidmar J, Loeschner K, Correia M, Larsen EH, Manser P, Wichser A, et al. Translocation of silver nanoparticles in the ex vivo human placenta perfusion model characterized by single particle ICP-MS. Nanoscale. 2018;10: 11980-91.
38. D'Errico JN, Doherty C, Fournier SB, Renkel N, Kallontzi S, Goedken M, et al. Identification and quantification of gold engineered nanomaterials and impaired fluid transfer across the rat placenta via ex vivo perfusion. Biomed Pharmacother. 2019;117:109148.

39. Buerki-Thurnherr T, von Mandach U, Wick P. Knocking at the door of the unborn child: engineered nanoparticles at the human placental barrier. Swiss Med Wkly. 2012;142:W13559.

40. Grafmüller S, Manser P, Krug HF, Wick P, von Mandach U. Determination of the transport rate of xenobiotics and nanomaterials across the placenta using the ex vivo human placental perfusion model. J Vis Exp. 2013; Available from: https://doi.org/10.3791/50401.

41. Grafmueller S, Manser P, Diener L, Diener P-A, Maeder-Althaus X, Maurizi L, et al. Bidirectional transfer study of polystyrene nanoparticles across the placental barrier in an ex vivo human placental perfusion model. Environ Health Perspect. 2015;123:1280-6.

42. Grafmueller S, Manser P, Diener L, Maurizi L, Diener P-A, Hofmann H, et al. Transfer studies of polystyrene nanoparticles in the ex vivo human placenta perfusion model: key sources of artifacts. Sci Technol Adv Mater. 2015;16: 044602.

43. Wick P, Malek A, Manser P, Meili D, Maeder-Althaus X, Diener L, et al. Barrier capacity of human placenta for nanosized materials. Environ Health Perspect. 2010;118:432-6.

44. Zhang Q, Ding Y, He K, Li H, Gao F, Moehling TJ, et al. Exposure to alumina nanoparticles in female mice during pregnancy induces neurodevelopmental toxicity in the offspring. Front Pharmacol. 2018;9:253

45. Austin CA, Umbreit TH, Brown KM, Barber DS, Dair BJ, Francke-Carroll S, et al. Distribution of silver nanoparticles in pregnant mice and developing embryos. Nanotoxicology. 2012;6:912-22.

46. Austin CA, Hinkley GK, Mishra AR, Zhang Q, Umbreit TH, Betz MW, et al. Distribution and accumulation of $10 \mathrm{~nm}$ silver nanoparticles in maternal tissues and visceral yolk sac of pregnant mice, and a potential effect on embryo growth. Nanotoxicology. 2016;10:654-61.

47. Campagnolo L, Massimiani M, Vecchione L, Piccirilli D, Toschi N, Magrini A, et al. Silver nanoparticles inhaled during pregnancy reach and affect the placenta and the foetus. Nanotoxicology. 2017;11:687-98.

48. Charehsaz M, Hougaard KS, Sipahi H, Ekici AID, Kaspar C,, Culha M, et al. Effects of developmental exposure to silver in ionic and nanoparticle form: a study in rats. Daru. 2016;24:24.

49. Elsharawy K, Abou-Dobara M, El-Gammal H, Hyder A. Chitosan coating does not prevent the effect of the transfer of green silver nanoparticles biosynthesized by Streptomyces malachitus into fetuses via the placenta. Reprod Biol. 2020;20:97-105.

50. Fatemi M, Moshtaghian J, Ghaedi K, Jafari Dinani N, Naderi G. Effects of silver nanoparticle on the developing liver of rat pups after maternal exposure. Iran J Pharm Res. 2017;16:685-93.

51. Fennell TR, Mortensen NP, Black SR, Snyder RW, Levine KE, Poitras E, et al. Disposition of intravenously or orally administered silver nanoparticles in pregnant rats and the effect on the biochemical profile in urine. J Appl Toxicol. 2017:37:530-44.

52. Lee Y, Choi J, Kim P, Choi K, Kim S, Shon W, et al. A transfer of silver nanoparticles from pregnant rat to offspring. Toxicol Res. 2012;28:139-41.

53. Melnik EA, Buzulukov YP, Demin VF, Demin VA, Gmoshinski IV, Tyshko NV, et al. Transfer of silver nanoparticles through the placenta and breast Milk during in vivo experiments on rats. Acta Nat. 2013;5:107-15.

54. Salim El, Abdel-Halim KY, Abu-Risha SE, Abdel-Latif AS. Induction of 8hydroxydeoxyguanosine and ultrastructure alterations by silver nanoparticles attributing to placental transfer in pregnant rats and fetuses. Hum Exp Toxicol. 2019;38:734-45.

55. Rattanapinyopituk K, Shimada A, Morita T, Sakurai M, Asano A, Hasegawa T, et al. Demonstration of the clathrin- and caveolin-mediated endocytosis at the maternal-fetal barrier in mouse placenta after intravenous administration of gold nanoparticles. J Vet Med Sci. 2014;76:377-87.

56. Sadauskas $E$, Wallin $H$, Stoltenberg $M$, Vogel $U$, Doering $P$, Larsen $A$, et al. Kupffer cells are central in the removal of nanoparticles from the organism. Part Fibre Toxicol. 2007:4:10.

57. Semmler-Behnke M, Lipka J, Wenk A, Hirn S, Schäffler M, Tian F, et al. Size dependent translocation and fetal accumulation of gold nanoparticles from maternal blood in the rat. Part Fibre Toxicol. 2014;11:33.

58. Tian X, Zhu M, Du L, Wang J, Fan Z, Liu J, et al. Intrauterine inflammation increases materno-fetal transfer of gold nanoparticles in a size-dependent manner in murine pregnancy. Small. 2013;9:2432-9. 
59. Tsyganova NA, Khairullin RM, Terentyuk GS, Khlebtsov BN, Bogatyrev VA, Dykman LA, et al. Penetration of pegylated gold nanoparticles through rat placental barrier. Bull Exp Biol Med. 2014;157:383-5.

60. Yang H, Du L, Wu G, Wu Z, Keelan JA. Murine exposure to gold nanoparticles during early pregnancy promotes abortion by inhibiting ectodermal differentiation. Mol Med. 2018;24:62.

61. Yang H, Sun C, Fan Z, Tian X, Yan L, Du L, et al. Effects of gestational age and surface modification on materno-fetal transfer of nanoparticles in murine pregnancy. Sci Rep. 2012;2:847.

62. Chu M, Wu Q, Yang H, Yuan R, Hou S, Yang Y, et al. Transfer of quantum dots from pregnant mice to pups across the placental barrier. Small. 2010;6: 670-8.

63. Liu J, Yang C, Liu J, Hu R, Hu Y, Chen H, et al. Effects of cd-based quantum dot exposure on the reproduction and offspring of Kunming mice over multiple generations. Nanotheranostics. 2017;1:23-37.

64. Hong W, Kuang H, He X, Yang L, Yang P, Chen B, et al. CdSe/ZnS Quantum Dots Impaired the First Two Generations of Placenta Growth in an Animal Model, Based on the Shh Signaling Pathway. Nanomaterials (Basel). 2019;9 Available from: https://doi.org/10.3390/nano9020257.

65. Zhang W, Yang L, Kuang H, Yang P, Aguilar ZP, Wang A, et al. Acute toxicity of quantum dots on late pregnancy mice: effects of nanoscale size and surface coating. J Hazard Mater. 2016;318:61-9.

66. Blum JL, Xiong JQ, Hoffman C, Zelikoff JT. Cadmium associated with inhaled cadmium oxide nanoparticles impacts fetal and neonatal development and growth. Toxicol Sci. 2012;126:478-86.

67. Zhong H, Geng Y, Chen J, Gao R, Yu C, Yang Z, et al. Maternal exposure to $\mathrm{CeO}(2) N P s$ during early pregnancy impairs pregnancy by inducing placental abnormalities. J Hazard Mater. 2020;389 Radarweg 29, 1043 Nx Amsterdam, Netherlands: Elsevier. Available from: https://doi.org/10.1016/j.jhazmat.2019. 121830.

68. Adamcakova-Dodd A, Monick MM, Powers LS, Gibson-Corley KN, Thorne PS. Effects of prenatal inhalation exposure to copper nanoparticles on murine dams and offspring. Part Fibre Toxicol. 2015;12:30.

69. Di Bona KR, Xu Y, Ramirez PA, DeLaine J, Parker C, Bao Y, et al. Surface charge and dosage dependent potential developmental toxicity and biodistribution of iron oxide nanoparticles in pregnant CD-1 mice. Reprod Toxicol. 2014;50:36-42.

70. Pinto SR, Helal-Neto E, Paumgartten F, Felzenswalb I, Araujo-Lima CF, Martínez-Máñez R, et al. Cytotoxicity, genotoxicity, transplacental transfer and tissue disposition in pregnant rats mediated by nanoparticles: the case of magnetic core mesoporous silica nanoparticles. Artif Cells Nanomed Biotechnol. 2018:46:527-38

71. Sweeney S, Adamcakova-Dodd A, Thorne PS, Assouline JG. Multifunctional nanoparticles for real-time evaluation of toxicity during fetal development. PLoS One. 2018;13:e0192474.

72. Park EJ. H k. effects of platinum nanoparticles on the postnatal development of mouse pups by maternal exposure. Environ Toxicol. 2010;25:279-86.

73. Yamashita K, Yoshioka Y, Higashisaka K, Mimura K, Morishita Y, Nozaki M, et al. Silica and titanium dioxide nanoparticles cause pregnancy complications in mice. Nat Nanotechnol. 2011;6:321-8.

74. Pietroiusti A, Vecchione L, Malvindi MA, Aru C, Massimiani M, Camaioni A, et al. Relevance to investigate different stages of pregnancy to highlight toxic effects of nanoparticles: the example of silica. Toxicol Appl Pharmacol. 2018;342:60-8

75. Elbastawisy YM, Almasry SM. Histomorphological evaluation of maternal and neonatal distal airspaces after maternal intake of nanoparticulate titanium dioxide: an experimental study in Wistar rats. J Mol Histol. 2014;45:91-102.

76. Hong F, Zhou Y, Zhao X, Sheng L, Wang L. Maternal exposure to nanosized titanium dioxide suppresses embryonic development in mice. Int J Nanomedicine. 2017;12:6197-204.

77. Hougaard KS, Jackson P, Jensen KA, Sloth JJ, Löschner K, Larsen EH, et al. Effects of prenatal exposure to surface-coated nanosized titanium dioxide (UV-titan). A study in mice. Part Fibre Toxicol. 2010;7:16

78. Mohammadipour A, Fazel A, Haghir H, Motejaded F, Rafatpanah H, Zabihi H, et al. Maternal exposure to titanium dioxide nanoparticles during pregnancy; impaired memory and decreased hippocampal cell proliferation in rat offspring. Environ Toxicol Pharmacol. 2014;37:617-25.

79. Notter T, Aengenheister L, Weber-Stadlbauer U, Naegeli H, Wick P, Meyer U, et al. Prenatal exposure to TiO2 nanoparticles in mice causes behavioral deficits with relevance to autism spectrum disorder and beyond. Transl Psychiatry. 2018;8:193.
80. Takeda K, Suzuki K-I, Ishihara A, Kubo-Irie M, Fujimoto R, Tabata M, et al. Nanoparticles transferred from pregnant mice to their offspring can damage the genital and cranial nerve systems. J Health Sci. 2009;55:95-102.

81. Zhou Y, Ji J, Hong F, Zhuang J, Wang L. Maternal exposure to Nanoparticulate titanium dioxide causes inhibition of hippocampal development involving dysfunction of the rho/NMDAR signaling pathway in offspring. J Biomed Nanotechnol. 2019;15:839-47.

82. Hong J-S, Park M-K, Kim M-S, Lim J-H, Park G-J, Maeng E-H, et al. Effect of zinc oxide nanoparticles on dams and embryo-fetal development in rats. Int J Nanomedicine. 2014;9(Suppl 2):145-57.

83. Lee J, Yu W-J, Song J, Sung C, Jeong EJ, Han J-S, et al. Developmental toxicity of intravenously injected zinc oxide nanoparticles in rats. Arch Pharm Res. 2016;39:1682-92

84. Jo E, Seo G, Kwon J-T, Lee M, Lee BC, Eom I, et al. Exposure to zinc oxide nanoparticles affects reproductive development and biodistribution in offspring rats. J Toxicol Sci. 2013;38:525-30.

85. Teng C, Jia J, Wang Z, Sharma VK, Yan B. Size-dependent maternal-fetal transfer and fetal developmental toxicity of $\mathrm{ZnO}$ nanoparticles after oral exposures in pregnant mice. Ecotoxicol Environ Saf. 2019;182:109439.

86. Wang Z, Zhang C, Huang F, Liu X, Wang Z, Yan B. Breakthrough of ZrO2 nanoparticles into fetal brains depends on developmental stage of maternal placental barrier and fetal blood-brain-barrier. J Hazard Mater. 2020;402: 123563.

87. Snyder RW, Fennell TR, Wingard CJ, Mortensen NP, Holland NA, Shannahan $\mathrm{JH}$, et al. Distribution and biomarker of carbon-14 labeled fullerene C60 $([(14) C(U)] C 60)$ in pregnant and lactating rats and their offspring after maternal intravenous exposure. J Appl Toxicol. 2015;35:1438-51.

88. Sumner SCJ, Fennell TR, Snyder RW, Taylor GF, Lewin AH. Distribution of carbon-14 labeled C60 ([14C]C60) in the pregnant and in the lactating dam and the effect of $\mathrm{C} 60$ exposure on the biochemical profile of urine. J Appl Toxicol. 2010;30:354-60.

89. Ho D, Leong JW, Crew RC, Norret M, House MJ, Mark PJ, et al. Maternalplacental-fetal biodistribution of multimodal polymeric nanoparticles in a pregnant rat model in mid and late gestation. Sci Rep. 2017;7:2866.

90. Kenesei K, Murali K, Czéh Á, Piella J, Puntes V, Madarász E. Enhanced detection with spectral imaging fluorescence microscopy reveals tissue- and cell-type-specific compartmentalization of surface-modified polystyrene nanoparticles. J Nanobiotechnology. 2016;14:55.

91. Bernal-Meléndez E, Lacroix M-C, Bouillaud P, Callebert J, Olivier B, Persuy M$A$, et al. Repeated gestational exposure to diesel engine exhaust affects the fetal olfactory system and alters olfactory-based behavior in rabbit offspring. Part Fibre Toxicol. 2019;16:5.

92. Valentino SA, Tarrade A, Aioun J, Mourier E, Richard C, Dahirel M, et al. Maternal exposure to diluted diesel engine exhaust alters placental function and induces intergenerational effects in rabbits. Part Fibre Toxicol. 2016;13:39.

93. Raia-Barjat T, Prieux C, Leclerc L, Sarry G, Grimal L, Chauleur C, et al. Elemental fingerprint of human amniotic fluids and relationship with potential sources of maternal exposure. J Trace Elem Med Biol. 2020;60: 126477.

94. Janssen BG, Madhloum N, Gyselaers W, Bijnens E, Clemente DB, Cox B, et al. Cohort Profile: The ENVIRonmental influence ON early AGEing (ENVI RONAGE): a birth cohort study. Int J Epidemiol. 2017:46:1386-7m.

95. Müller R, Gläser M, Göhner C, Seyfarth L, Schleussner E, Hofmann A, et al. In situ measurements of magnetic nanoparticles after placenta perfusion. J Magn Magn Mater. 2015;380:66-71.

96. Elsaesser A, Taylor A, de Yanés GS, McKerr G, Kim E-M, O'Hare E, et al. Quantification of nanoparticle uptake by cells using microscopical and analytical techniques. Nanomedicine. 2010;5:1447-57.

97. Vanhecke D, Rodriguez-Lorenzo L, Clift MJD, Blank F, Petri-Fink A, RothenRutishauser B. Quantification of nanoparticles at the single-cell level: an overview about state-of-the-art techniques and their limitations. Nanomedicine. 2014;9:1885-900.

98. Verdaasdonk JS, Stephens AD, Haase J, Bloom K. Bending the Rules: Widefield Microscopy and the Abbe Limit of Resolution. J Cell Physiol. 2014: 132-8 Available from: https://doi.org/10.1002/jcp.24439.

99. Ostrowski A, Nordmeyer D, Boreham A, Holzhausen C, Mundhenk L, Graf C, et al. Overview about the localization of nanoparticles in tissue and cellular context by different imaging techniques. Beilstein J Nanotechnol. 2015;6: 263-80.

100. Pawley J. Handbook of biological confocal microsopcy. Boston: Springer Science \& Business Media 2010. 
101. Leblond F, Davis SC, Valdés PA, Pogue BW. Pre-clinical whole-body fluorescence imaging: review of instruments, methods and applications. J Photochem Photobiol B. 2010;98:77-94.

102. Mansfield JR, Hoyt C, Levenson RM. Visualization of microscopy-based spectral imaging data from multi-label tissue sections. Curr Protoc Mol Biol. 2008:84:6248.

103. Levenson R, Beechem J, McNamara G. Spectral imaging in preclinical research and clinical pathology. Stud Health Technol Inform. 2013;185:4375

104. Fagerland JA, Wall HG, Pandher K, LeRoy BE, Gagne GD. Ultrastructural analysis in preclinical safety evaluation. Toxicol Pathol. 2012;40:391-402.

105. Bové H, Steuwe C, Fron E, Slenders E, D'Haen J, Fujita Y, et al. Biocompatible label-free detection of carbon Black particles by femtosecond pulsed laser microscopy. Nano Lett. 2016;16:3173-8.

106. Tang M-X, Mulvana H, Gauthier T, Lim AKP, Cosgrove DO, Eckersley RJ, et al. Quantitative contrast-enhanced ultrasound imaging: a review of sources of variability. Interface Focus. 2011;1:520-39.

107. Chu YS, Yi JM, De Carlo F, Shen Q, Lee W-K, Wu HJ, et al. Hard-x-ray microscopy with Fresnel zone plates reaches $40 \mathrm{~nm}$ Rayleigh resolution. Appl Phys Lett. 2008:103119 Available from: https://doi.org/10.1063/1. 2857476.

108. Adams F. Synchrotron X-ray fluorescence analysis in environmental and earth sciences. EPJ Web of Conferences EDP Sciences. 2010;9:165-80.

109. Singh AK. Experimental Methodologies for the Characterization of Nanoparticles. Eng Nanoparticles. 2016:125-70 Available from: https://doi. org/10.1016/b978-0-12-801406-6.00004-2.

110. Taylor HE, Taylor HM. Inductively Coupled Plasma-Mass Spectrometry: Practices and Techniques. San Diego: Academic Press; 2001.

111. Mozhayeva D, Engelhard C. A critical review of single particle inductively coupled plasma mass spectrometry - A step towards an ideal method for nanomaterial characterization. J Anal At Spectrom. 2020; [cited 2020 Apr 23]. Royal Society of Chemistry. Available from: https://pubs.rsc.org/en/ content/articlehtml/2019/ja/c9ja00206e?page=search .

112. de la Calle I, Menta M, Klein M, Séby F. Screening of TiO2 and au nanoparticles in cosmetics and determination of elemental impurities by multiple techniques (DLS, SP-ICP-MS, ICP-MS and ICP-OES). Talanta. 2017; 171:291-306.

113. Zachariadis GA, Sahanidou E. Multi-element method for determination of trace elements in sunscreens by ICP-AES. J Pharm Biomed Anal. 2009:342-8 Available from: https://doi.org/10.1016/j.jpba.2009.05.003.

114. Gräfe C, Slabu I, Wiekhorst F, Bergemann C, von Eggeling F, Hochhaus A, et al. Magnetic particle spectroscopy allows precise quantification of nanoparticles after passage through human brain microvascular endothelial cells. Phys Med Biol. 2016;61:3986-4000.

115. Behzadi S, Ghasemi F, Ghalkhani M, Ashkarran AA, Akbari SM, Pakpour S, et al. Determination of nanoparticles using UV-Vis spectra. Nanoscale. 2015; 7:5134-9.

116. Haiss W, Thanh NTK, Aveyard J, Fernig DG. Determination of size and concentration of gold nanoparticles from UV-vis spectra. Anal Chem. 2007; 79:4215-21.

117. Zhang $H$, Lyden D. Asymmetric-flow field-flow fractionation technology for exomere and small extracellular vesicle separation and characterization. Nat Protoc. 2019:14:1027-53.

118. vd Kammer F, Baborowski M, Friese K. Application of a high-performance liquid chromatography fluorescence detector as a nephelometric turbidity detector following Field-Flow Fractionation to analyse size distributions of environmental colloids. J Chromatogr A. 2005;1100:81-9.

119. Vandamme TF. Use of rodents as models of human diseases. J Pharm Bioallied Sci. 2014;6:2-9.

120. Fischer B, Chavatte-Palmer P, Viebahn C, Navarrete Santos A, Duranthon V. Rabbit as a reproductive model for human health. Reproduction. 2012;144 $1-10$.

121. Furukawa S, Kuroda Y, Sugiyama A. A comparison of the histological structure of the placenta in experimental animals. J Toxicol Pathol. 2014;27: 11-8.

122. Carter AM. Evolution of placental function in mammals: the molecular basis of gas and nutrient transfer, hormone secretion, and immune responses. Physiol Rev. 2012;92:1543-76.

123. Malassine A, Frendo J-L, Evain-Brion D. A comparison of placental development and endocrine functions between the human and mouse model. Hum Reprod Update. 2003;9:531-9 Oxford University Press.
124. Carter A, Enders A, Jones C, Mess A, Pfarrer C, Pijnenborg R, et al. Comparative Placentation and Animal Models: Patterns of Trophoblast Invasion - A Workshop Report [Internet]. Placenta. 2006:30-3 Available from: https://doi.org/10.1016/j.placenta.2006.01.008.

125. Carter AM. Animal Models of Human Placentation - A Review [Internet] Placenta. 2007:S41-7 Available from: https://doi.org/10.1016/j.placenta.2006. 11.002 .

126. Conings S, Amant F, Annaert P, Van Calsteren K. Integration and validation of the ex vivo human placenta perfusion model. J Pharmacol Toxicol Methods. 2017:88:25-31.

127. Karttunen V, Mohammed AM, Vähäkangas K. Chapter 67- The Significance of $A B C$ Transporters in Human Placenta for the Exposure of Fetus to Xenobiotics. Reprod Dev Toxicol. 2017:1275-300.

128. Nikitina L, Dohr G, Juch H. Studying nanoparticle interaction with human placenta: Festina lente! Nanotoxicology. 2015:9(Suppl 1):133-4.

129. Kasurinen S, Happo MS, Rönkkö TJ, Orasche J, Jokiniemi J, Kortelainen M, et al. Differences between co-cultures and monocultures in testing the toxicity of particulate matter derived from log wood and pellet combustion. PLoS One. 2018:13:e0192453.

130. Kämpfer AAM, Urbán P, Gioria S, Kanase N, Stone V, Kinsner-Ovaskainen A. Development of an in vitro co-culture model to mimic the human intestine in healthy and diseased state. Toxicol in Vitro. 2017;45:31-43.

131. Bosco C. Alcohol and xenobiotics in placenta damage. Comprehensive handbook of alcohol related pathology. San Diego: Academic Press; 2005. p. 921-35.

132. Hougaard KS, Campagnolo L, Chavatte-Palmer P, Tarrade A, RousseauRalliard D, Valentino $S$, et al. A perspective on the developmental toxicity of inhaled nanoparticles. Reprod Toxicol. 2015;56:118-40.

133. Benet LZ. Effect of route of administration and distribution on drug action. J Pharmacokinet Biopharm. 1978;6:559-85.

134. Strojan K, Leonardi A, Bregar VB, Križaj I, Svete J, Pavlin M. Dispersion of nanoparticles in different media importantly determines the composition of their protein Corona. PLoS One. 2017:12:e0169552.

135. Ding L, Yao C, Yin X, Li C, Huang Y, Wu M, et al. Size, shape, and protein Corona determine cellular uptake and removal mechanisms of gold nanoparticles. Small. 2018;14:e1801451.

136. Lundqvist M, Stigler J, Cedervall T, Berggård T, Flanagan MB, Lynch I, et al. The evolution of the protein corona around nanoparticles: a test study. ACS Nano. 2011:5:7503-9.

137. Carney EW, Scialli AR, Watson RE, DeSesso JM. Mechanisms regulating toxicant disposition to the embryo during early pregnancy: an interspecies comparison. Birth Defects Res C Embryo Today. 2004;72:345-60.

138. Theiler K. The house mouse: atlas of embryonic development. New York: Springer Science \& Business Media; 1989.

139. Altman PL, Dittmer DS, et al. Growth, including reproduction and morphological development. Growth, including reproduction and morphological development [Internet]. Washington: Federation of American Societies for Experimental Biology; 1962. Available from: https://www. cabdirect.org/cabdirect/abstract/19631603969.

140. EDWARDS MJ. The external development of the rabbit and rat embryo. Adv Teratol. 1968;3:239-63.

141. O'Rahilly R, Müller F. Developmental stages in human embryos: revised and new measurements. Cells Tissues Organs. 2010;192:73-84.

142. Kreyling WG, Hirn S, Möller W, Schleh C. Wenk A, Celik G, et al. Air-blood barrier translocation of Tracheally instilled gold nanoparticles inversely depends on particle size. ACS Nano. Am Chem Soc. 2014:8:222-33.

143. Bouccara S, Sitbon G, Fragola A, Loriette V, Lequeux N, Pons T. Enhancing fluorescence in vivo imaging using inorganic nanoprobes. Curr Opin Biotechnol. 2015;34:65-72.

144. Tenuta T, Monopoli MP, Kim J, Salvati A, Dawson KA, Sandin P, et al. Elution of labile fluorescent dye from nanoparticles during biological use. PLoS One. 2011;6:e25556

145. Klymchenko AS, Roger E, Anton N, Anton H, Shulov I, Vermot J, et al. Highly lipophilic fluorescent dyes in nano-emulsions: towards bright non-leaking nano-droplets. RSC Adv. 2012:2:11876-86.

146. Peters R, Herrera-Rivera Z, Undas A, van der Lee M, Marvin H, Bouwmeester $\mathrm{H}$, et al. Single particle ICP-MS combined with a data evaluation tool as a routine technique for the analysis of nanoparticles in complex matrices. Anal At Spectrom. 2015:30:1274-85 The Royal Society of Chemistry.

147. Degueldre C, Favarger P-Y. Colloid analysis by single particle inductively coupled plasma-mass spectroscopy: a feasibility study. Colloids Surf A Physicochem Eng Asp. 2003;217:137-42. 
148. Giddings JC. Field-flow fractionation: analysis of macromolecular, colloidal, and particulate materials. Science. 1993;260:1456-65.

149. Itoh N, Sano A, Santa T, Kato M. Simultaneous analysis of nanoparticles and small molecules by high-performance liquid chromatography using a silica monolithic column. Analyst. 2014;139:4453-7.

150. Mourdikoudis S, Pallares RM, Thanh NTK. Characterization techniques for nanoparticles: comparison and complementarity upon studying nanoparticle properties. Nanoscale. 2018;10:12871-934.

\section{Publisher's Note}

Springer Nature remains neutral with regard to jurisdictional claims in published maps and institutional affiliations.

Ready to submit your research? Choose BMC and benefit from:

- fast, convenient online submission

- thorough peer review by experienced researchers in your field

- rapid publication on acceptance

- support for research data, including large and complex data types

- gold Open Access which fosters wider collaboration and increased citations

- maximum visibility for your research: over $100 \mathrm{M}$ website views per year

At $\mathrm{BMC}$, research is always in progress.

Learn more biomedcentral.com/submissions 